\title{
Long-range transport pathways of tropospheric source gases originating in Asia into the northern lower stratosphere during the Asian monsoon season 2012
}

\author{
Bärbel Vogel ${ }^{1}$, Gebhard Günther ${ }^{1}$, Rolf Müller ${ }^{1}$, Jens-Uwe Grooß ${ }^{1}$, Armin Afchine ${ }^{1}$, Heiko Bozem ${ }^{2}$, Peter Hoor ${ }^{2}$, \\ Martina Krämer $^{1}$, Stefan Müller ${ }^{2}$, Martin Riese ${ }^{1}$, Christian Rolf ${ }^{1}$, Nicole Spelten ${ }^{1}$, Gabriele P. Stiller ${ }^{3}$, \\ Jörn Ungermann ${ }^{1}$, and Andreas Zahn ${ }^{3}$ \\ ${ }^{1}$ Forschungszentrum Jülich, Institute of Energy and Climate Research - Stratosphere (IEK-7), Jülich, Germany \\ ${ }^{2}$ Institute for Atmospheric Physics, University of Mainz, Mainz, Germany \\ ${ }^{3}$ Institute of Meteorology and Climate Research, Karlsruhe Institute of Technology, Karlsruhe, Germany
}

Correspondence to: Bärbel Vogel (b.vogel@fz-juelich.de)

Received: 30 May 2016 - Published in Atmos. Chem. Phys. Discuss.: 23 June 2016

Revised: 6 September 2016 - Accepted: 30 September 2016 - Published: 9 December 2016

\begin{abstract}
Global simulations with the Chemical Lagrangian Model of the Stratosphere (CLaMS) using artificial tracers of air mass origin are used to analyze transport mechanisms from the Asian monsoon region into the lower stratosphere. In a case study, the transport of air masses from the Asian monsoon anticyclone originating in India/China by an eastward-migrating anticyclone which broke off from the main anticyclone on 20 September 2012 and filaments separated at the northeastern flank of the anticyclone are analyzed. Enhanced contributions of young air masses (younger than 5 months) are found within the separated anticyclone confined at the top by the thermal tropopause. Further, these air masses are confined by the anticyclonic circulation and, on the polar side, by the subtropical jet such that the vertical structure resembles a bubble within the upper troposphere. Subsequently, these air masses are transported eastwards along the subtropical jet and enter the lower stratosphere by quasi-horizontal transport in a region of double tropopauses most likely associated with Rossby wave breaking events. As a result, thin filaments with enhanced signatures of tropospheric trace gases were measured in the lower stratosphere over Europe during the TACTS/ESMVal campaign in September 2012 in very good agreement with CLaMS simulations. Our simulations demonstrate that source regions in Asia and in the Pacific Ocean have a significant impact on the chemical composition of the lower stratosphere of the Northern Hemisphere. Young, moist air masses, in particular at
\end{abstract}

the end of the monsoon season in September/October 2012, flooded the extratropical lower stratosphere in the Northern Hemisphere with contributions of up to $\approx 30 \%$ at $380 \mathrm{~K}$ (with the remaining fraction being aged air). In contrast, the contribution of young air masses to the Southern Hemisphere is much lower. At the end of October 2012, approximately 1.5 ppmv $\mathrm{H}_{2} \mathrm{O}$ is found in the lower Northern Hemisphere stratosphere (at $380 \mathrm{~K}$ ) from source regions both in Asia and in the tropical Pacific compared to a mean water vapor content of $\approx 5$ ppmv. In addition to this main transport pathway from the Asian monsoon anticyclone to the east along the subtropical jet and subsequent transport into the northern lower stratosphere, a second horizontal transport pathway out of the anticyclone to the west into the tropics (TTL) is found in agreement with MIPAS HCFC-22 measurements.

\section{Introduction}

The Asian summer monsoon is associated with strong upward transport of tropospheric source gases by deep convection. Uplifted tropospheric air masses are confined by a strong anticyclonic circulation in the upper troposphere, which acts as a transport barrier (e.g., Li et al., 2005; Randel and Park, 2006; Park et al., 2007, 2008, 2009; Ploeger et al., 2015). In summer 2012, enhanced tropospheric trace gases were found in the upper troposphere over Asia from mid- 
June to late October both during the existence of the Asian monsoon anticyclone and after its breakup (Vogel et al., 2015). Studies for summer 2012 show that air masses from the Asian monsoon impact the chemical composition of the lower stratosphere over northern Europe, in particular at the end of the monsoon season in September and October 2012 (Vogel et al., 2014, 2015; Müller et al., 2016). An increase in the concentrations of tropospheric source gases such as $\mathrm{CO}$, $\mathrm{H}_{2} \mathrm{O}$, and $\mathrm{N}_{2} \mathrm{O}$ and a decrease of the stratospheric tracer $\mathrm{O}_{3}$ was identified by in situ aircraft measurements in the lower stratosphere over Europe from summer to autumn 2012, associated with transport from the Asian monsoon anticyclone (Müller et al., 2016).

The identification and the relative importance of different transport pathways of tropospheric source gases found within the Asian monsoon anticyclone into the lower stratosphere are the subject of a longstanding debate (Dethof et al., 1999; Park et al., 2004; Randel et al., 2010; Bian et al., 2012; Bourassa et al., 2012; Ploeger et al., 2013; Fairlie et al., 2014; Fromm et al., 2014; Uma et al., 2014; Vogel et al., 2014, 2015; Garny and Randel, 2016; Tissier and Legras, 2016; Orbe et al., 2015). The influence of these different transport pathways on the chemical composition of the extratropical upper troposphere and lower stratosphere (ExUTLS) is important because changes in ozone and water vapor in the ExUTLS have a significant impact on surface climate, even if the perturbation is relatively small. Thus, changes in the chemical composition in this part of the Earth's atmosphere play a crucial role for climate change (e.g., Solomon et al., 2010; Riese et al., 2012; Hossaini et al., 2015). Moreover, increasing stratospheric water vapor has the potential to affect stratospheric chemistry (e.g., Kirk-Davidoff et al., 1999; Dvortsov and Solomon, 2001; Vogel et al., 2011a; Anderson et al., 2012) and can influence the formation of cirrus clouds in the lower stratosphere (Spang et al., 2015). Further, it is discussed that enhanced water vapor in combination with pollution in the Asian monsoon region may play an important role in the formation of the Asian tropopause aerosol layer (ATAL), which causes regional radiative forcing (Vernier et al., 2015).

One important mechanism for the long-range transport of air masses from the Asian monsoon anticyclone to the extratropical lower stratosphere is the separation of air masses at the northeastern flank of the anticyclone caused by disturbances of the subtropical jet by strong Rossby waves and subsequent eastward transport of these air masses within the tropics along the subtropical jet (Dethof et al., 1999; Vogel et al., 2014, 2015). In particular, eastward-migrating anticyclones break off from the main anticyclone a few times each summer (Dethof et al., 1999; Hsu and Plumb, 2001; Popovic and Plumb, 2001; Garny and Randel, 2013; Vogel et al., 2014; Ungermann et al., 2016) and have the potential to carry air with high amounts of tropospheric trace gases from the Asian monsoon anticyclone to middle and high latitudes of the Northern Hemisphere. These young air masses can be transported into the extratropical lower stratosphere where they are eventually mixed irreversibly with the surrounding aged stratospheric air (Dethof et al., 1999; Garny and Randel, 2013; Vogel et al., 2014), thus affecting the chemical and radiative balance of the extratropical lower stratosphere. However, the exact transport mechanisms of young air masses from the troposphere, including air originating within the Asian monsoon anticyclone into the lower stratosphere, are yet to be identified and quantified.

Trajectory calculations show that tropospheric air masses at the southeast edge of the anticyclonic circulation over southeast Asia may be uplifted to the outer anticyclonic circulation by a typhoon to levels of potential temperature of $\approx 370 \mathrm{~K}$ (Vogel et al., 2014). Subsequent upward transport of these air masses occurs in a clockwise upward spiral around the core of the Asian monsoon anticyclone to levels of potential temperature around $380 \mathrm{~K}$. Moreover, Vogel et al. (2014) demonstrated that the combination of very rapid uplift by a typhoon and eastward eddy shedding from the Asian monsoon anticyclone is an additional rapid transport pathway $(\approx 5$ weeks $)$ connecting surface air with enhanced signatures of tropospheric trace gases measured in the lower stratosphere over northern Europe.

Here, we use in situ measurements obtained during two aircraft campaigns TACTS and ESMVal, jointly undertaken in August and September 2012, using the German High Altitude and LOng Range Research Aircraft (HALO). Backward trajectory calculations (Vogel et al., 2014; Müller et al., 2016) show that enhanced tropospheric trace gases which were measured over northern Europe in the extratropical lower stratosphere during the TACTS/ESMVal campaign in August and September 2012 are affected by air masses from the circulation of the Asian monsoon anticyclone or which originate in the Asian monsoon anticyclone itself.

Further model simulations with the Chemical Lagrangian Model of the Stratosphere (CLaMS) using artificial emission tracers for different regions on the Earth's surface (Vogel et al., 2015) demonstrate that the chemical composition of the lower stratosphere of the Northern Hemisphere is influenced by a combination of young, freshly injected air and aged air. The composition of the young air masses is dominated by air masses primarily originating in India, China, and southeast Asia, in particular at the end of the monsoon season in September/October 2012. Thus, the Asian monsoon anticyclone and boundary emissions from Asia contribute to the maximum of tropospheric signatures found in the northern extratropical lower stratosphere in boreal summer and autumn (e.g., Hoor et al., 2005; Hegglin and Shepherd, 2007; Bönisch et al., 2009; Zahn et al., 2014; Müller et al., 2016), sometimes also referred to as "flushing" of the lower stratosphere (Hegglin and Shepherd, 2007; Bönisch et al., 2009).

The exchange of air masses from the troposphere to the stratosphere primarily occurs in poleward flow structures such as tropospheric intrusions (e.g., Fairlie et al., 2007; Sprenger et al., 2007; Pan et al., 2009; Vogel et al., 2011b). 
These intrusions develop into elongated potential vorticity (PV) streamers and are a manifestation of Rossby wave breaking. Rossby wave breaking is identified as an important mechanism for the exchange of air masses between the tropical upper troposphere and the extratropical lower stratosphere with a pronounced peak during summer in each hemisphere controlled by the presence of monsoon anticyclones, in particular of the Asian monsoon (e.g., Homeyer and Bowman, 2013; Kunz et al., 2015). High frequencies of PV streamers are found over the eastern North Pacific and over the Atlantic in summer as demonstrated in a recently published climatology of PV streamers (Kunz et al., 2015).

In addition to this large-scale transport process of water vapor by air mass exchange between the tropics and the extratropics, convection-induced injections of water vapor in midlatitudes can also occur in large storm systems such as tropical cyclones and by deep continental convection (e.g., Anderson et al., 2012; Homeyer et al., 2014; Vogel et al., 2014).

In this paper, we identify in detail the transport mechanisms of air masses originating in boundary source regions in Asia and separated from the Asian monsoon anticyclone by eastward eddy shedding into the lower stratosphere over northern Europe including mixing processes. The same model simulation as in Vogel et al. (2015) with the CLaMS model (e.g., Pommrich et al., 2014, and references therein) is used, including artificial emission tracers that mark source regions in the boundary layer of the Earth's atmosphere. This allows the origin of the air masses and the detailed transport pathways from Asian source regions into the northern lower stratosphere to be quantified. Further, in CLaMS the irreversible part of transport, i.e., mixing, is controlled by the local horizontal strain and vertical shear rates with mixing parameters deduced from observations (Konopka et al., 2012, and references therein) and therefore allows mixing processes in the lower stratosphere, as shown in several previous studies, to be characterized (e.g., Pan et al., 2006; Vogel et al., 2011b; Konopka and Pan, 2012). Small-scale structures, indicating the impact of young tropospheric air masses within the lower stratosphere measured during the TACTS/ESMVal aircraft campaign in September 2012, are compared with results of CLaMS model simulations to identify their origin and the associated transport pathways. Finally, the impact of boundary source regions in Asia on the composition of the extratropical Northern Hemisphere is calculated.

The paper is organized as follows: Sect. 2 describes the in situ measurements and Sect. 3 the setup used for CLaMS simulations. In Sect. 4, CLaMS results are presented and compared to measurements. A short discussion and conclusions are given in Sect. 5.

\section{TACTS/ESMVal measurements over Europe}

Here, we use in situ measurements performed during two aircraft campaigns TACTS and ESMVal, jointly conducted in August and September 2012. TACTS was designed to study "transport and composition in the upper troposphere and lowermost stratosphere". The objective of the ESMVal (Earth System Model Validation) measurement campaign was to validate model simulations with measurements ranging from the Southern to the Northern Hemisphere (here from $65^{\circ} \mathrm{S}$ to $80^{\circ} \mathrm{N}$ ). Both campaigns were performed using the German HALO aircraft, a Gulfstream V. During the TACTS/ESMVal campaign, 13 research flights were performed, the most of them over northern Europe. Here, we discuss the last three flights conducted on 23, 25, and 26 September 2012. Measurements from the following in situ instruments on board the HALO aircraft are used:

- Carbon monoxide (CO) and methane $\left(\mathrm{CH}_{4}\right)$ measurements are used from TRIHOP, a three-channel quantum cascade laser infrared absorption spectrometer (for more details, see Müller et al., 2016), which is an updated version of the three-channel tunable diode laser instrument for atmospheric research (TRISTAR) used in previous aircraft campaigns (e.g., Hoor et al., 2004).

- Water vapor $\left(\mathrm{H}_{2} \mathrm{O}\right)$ measurements were obtained from the Fast In situ Stratospheric Hygrometer (FISH), which is based on the Lyman- $\alpha$ photofragment fluorescence technique (Zöger et al., 1999). The FISH inlet was mounted facing forward to measure total water which is the sum of gas-phase water and water in ice particles. A correction procedure is applied to calculate gas-phase water from FISH measurements in clouds (for more details, see Meyer et al., 2015).

- Ozone $\left(\mathrm{O}_{3}\right)$ was measured with FAIRO, a lightweight $(14.5 \mathrm{~kg})$ instrument with high accuracy $(2 \%)$ and high time resolution $(10 \mathrm{~Hz})$ developed for the HALO aircraft. FAIRO combines a dual-beam UV photometer with a UV-LED as a light source and a dry chemiluminescence detector (Zahn et al., 2012).

- Potential temperature $(\Theta)$ was deduced from the Basic HALO Measurement and Sensor System (BAHAMAS) that yields basic meteorological and avionic data for all TACTS/ESMVal flights.

\section{CLaMS simulations using artificial tracers of air mass origin}

We use the same model simulation with the threedimensional chemistry transport model CLaMS (McKenna et al., 2002b, a; Pommrich et al., 2014, and references therein) as in Vogel et al. (2015), covering the Asian monsoon season 2012. The CLaMS model has the capability to 


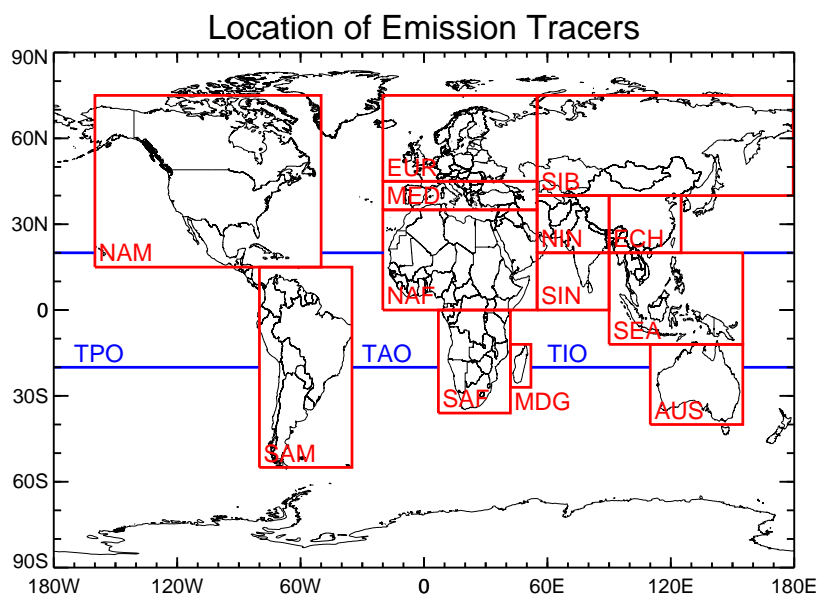

Figure 1. Global geographical location of artificial boundary layer source regions in the CLaMS model, also referred to as "emission tracers" (Vogel et al., 2015). The latitude and longitude range for each emission tracer is listed in Table 1.

reproduce the strong gradients of chemical species found in regions with strong transport barriers, such as the edge of the Asian monsoon anticyclone (e.g., Konopka et al., 2010; Ploeger et al., 2015; Vogel et al., 2015), the extratropical tropopause (e.g., Pan et al., 2006; Vogel et al., 2011b; Konopka and Pan, 2012), and the polar vortex (e.g., Günther et al., 2008; Vogel et al., 2008).

In brief, the global CLaMS simulation employed here covers an altitude range from the surface up to $900 \mathrm{~K}$ potential temperature $(\approx 37 \mathrm{~km}$ altitude) with a horizontal resolution of $100 \mathrm{~km}$ and a maximum vertical resolution of approximately $400 \mathrm{~m}$ near the tropopause. The model simulation is driven by horizontal winds from ERA-Interim reanalysis (Dee et al., 2011) provided by the European Centre for Medium-Range Weather Forecasts (ECMWF). For the vertical velocities, the diabatic approach was applied using the diabatic heating rate as the vertical velocity including latent heat release (for more details, see Ploeger et al., 2010). Further, CLaMS employs a hybrid coordinate $(\zeta)$, which transforms from a strictly isentropic coordinate $\Theta$ to a pressurebased coordinate system below a certain reference level (in this study $300 \mathrm{hPa}$ ) (for more details, see Konopka et al., 2012; Pommrich et al., 2014).

The CLaMS simulation covers the time period from 1 May to 31 October 2012, including the Asian monsoon season 2012. It includes full stratospheric chemistry (Grooß et al., 2014; Sander et al., 2011). Chemical species are initialized on 1 May 2012 mainly based on satellite data from AURAMLS (version 3.3) (Livesey et al., 2011) and ACE-FTS (version 3.0) (Waymark et al., 2013) measurements. At the upper boundary ( $900 \mathrm{~K}$ potential temperature), mainly AURAMLS and ACE-FTS measurements and tracer-tracer correlations were used (for more details, see Vogel et al., 2015).
Table 1. Latitude and longitude range of artificial boundary layer sources in the CLaMS model, also referred to as "emission tracers". The geographical position of each emission tracer is shown in Fig. 1.

\begin{tabular}{lrr}
\hline Emission tracer & Latitude & Longitude \\
\hline Northern India (NIN) & $20-40^{\circ} \mathrm{N}$ & $55-90^{\circ} \mathrm{E}$ \\
Southern India (SIN) & $0-20^{\circ} \mathrm{N}$ & $55-90^{\circ} \mathrm{E}$ \\
Eastern China (ECH) & $20-40^{\circ} \mathrm{N}$ & $90-125^{\circ} \mathrm{E}$ \\
Southeast Asia (SEA) & $12^{\circ} \mathrm{S}-20^{\circ} \mathrm{N}$ & $90-155^{\circ} \mathrm{E}$ \\
Siberia (SIB) & $40-75^{\circ} \mathrm{N}$ & $55-180^{\circ} \mathrm{E}$ \\
Europe (EUR) & $45-75^{\circ} \mathrm{N}$ & $20^{\circ} \mathrm{W}-55^{\circ} \mathrm{E}$ \\
Mediterranean (MED) & $35-45^{\circ} \mathrm{N}$ & $20^{\circ} \mathrm{W}-55^{\circ} \mathrm{E}$ \\
Northern Africa (NAF) & $0-35^{\circ} \mathrm{N}$ & $20^{\circ} \mathrm{W}-55^{\circ} \mathrm{E}$ \\
Southern Africa (SAF) & $36^{\circ} \mathrm{S}-0^{\circ} \mathrm{N}$ & $7-42^{\circ} \mathrm{E}$ \\
Madagascar (MDG) & $27-12^{\circ} \mathrm{S}$ & $42-52^{\circ} \mathrm{E}$ \\
Australia (AUS) & $40-12^{\circ} \mathrm{S}$ & $110-155^{\circ} \mathrm{E}$ \\
North America (NAM) & $15-75^{\circ} \mathrm{N}$ & $160-50^{\circ} \mathrm{W}$ \\
South America (SAM) & $55^{\circ} \mathrm{S}-15^{\circ} \mathrm{N}$ & $80-35^{\circ} \mathrm{W}$ \\
\hline Tropical Pacific Ocean (TPO) & $20^{\circ} \mathrm{S}-20^{\circ} \mathrm{N}$ & see Fig. 1 \\
Tropical Atlantic Ocean (TAO) & $20^{\circ} \mathrm{S}-20^{\circ} \mathrm{N}$ & see Fig. 1 \\
Tropical Indian Ocean (TIO) & $20^{\circ} \mathrm{S}-20^{\circ} \mathrm{N}$ & see Fig. 1 \\
Background & remaining surface \\
\hline
\end{tabular}

At the lower boundary (surface), $\mathrm{O}_{3}$ is set to a constant tropospheric volume mixing ratio of $4.8 \times 10^{-8}$ representing the ozone mixing ratio at $5 \mathrm{~km}$ (Brasseur and Solomon, 2005, p. 619). ECMWF water vapor is prescribed at lower model levels. In CLaMS simulations, both AIRS (Atmospheric Infrared Sounder) and MOPITT (Measurements of Pollution in the Troposphere) were previously used for constructing the boundary for CO in the troposphere (Vogel et al., 2011b; Konopka and Pan, 2012; Pommrich et al., 2014). Here, lower boundary conditions for $\mathrm{CO}$ and $\mathrm{CH} 4(\zeta<200 \mathrm{~K})$ are derived from AIRS version 6 satellite measurements following the approach described by Pommrich et al. (2014). The CO values prescribed at the lower boundary condition below the $\zeta=200 \mathrm{~K}$ level are scaled up by a factor of 1.5 (P. Konopka, personal communication, 2013) to correct for the underestimation of $\mathrm{CO}$ in the lower troposphere. $\mathrm{CH}_{4}$ values are not scaled.

In the CLaMS simulation used here, artificial tracers of air mass origin, referred to as "emission tracers", that globally mark all the regions in the Earth's boundary layer are implemented $(\approx 2-3 \mathrm{~km}$ above the surface following orography corresponding to $\zeta<120 \mathrm{~K}$ ), as shown in Fig. 1 and Table 1 . Within the boundary layer, the sum of all the different emission tracers $\left(\Omega_{i}\right)$ is equal to $1\left(\Omega=\sum_{i=1}^{n} \Omega_{i}=1\right)$. Air masses in the model boundary layer are marked by different emission tracers every $24 \mathrm{~h}$ (the time step for mixing in CLaMS). Thus, in our simulations, the transport of air masses from the model boundary layer up to the UTLS is considered from the response to a single pulse during $\left(t_{i}, t_{i}+\Delta t_{i}\right)$ for times $t>t_{i}$, with $t_{i}$ equal to 1 May 2012 and $\Delta t_{i}$ equal 
to 6 months marking young, freshly emitted air masses. We used this single-pulse approach because the paper focuses on analyzing the influence of fresh emissions from different boundary regions using the meteorological conditions of the year 2012. Transport and mixing of the emission tracers to other regions of the free troposphere or stratosphere occurs in a manner equivalent to all the chemical species included in the CLaMS simulation. The percentage of an individual emission tracer represents the contribution of the corresponding boundary layer region to the composition of an air parcel since 1 May 2012 considering advection and mixing. Thus, during the course of the simulation, the airmass fraction $f_{i}\left(r, t \mid \Omega_{i}\right)$ is defined as the fraction of air at a location $r$ and time $t$ (with $t_{i} \leq t \leq t_{i}+\Delta t_{i}$ ) that was emitted since $t_{i}$ within $\Delta t_{i}$ from the model boundary layer in region $\Omega_{i}$. Note, however, that our emission tracers only describe the contribution of young, freshly injected air masses from the boundary layer. Therefore, in our simulations presented here, the composition of an air mass in the free atmosphere will be a combination of young air masses and aged air masses originating in the free troposphere or stratosphere.

Emission tracers in CLaMS are designed to identify surface regions of the Earth's atmosphere that contribute to the composition of the Asian monsoon anticyclone and of the lower stratosphere during the course of the 2012 Asian monsoon season with a focus on the influence of fresh emissions. Therefore, the starting point for the CLaMS simulation was chosen a few weeks before the formation of the Asian monsoon anticyclone occurred. Thus, transport processes associated with the Asian monsoon anticyclone and horizontal transport from the TTL into the lower stratosphere are considered.

Vogel et al. (2015) showed that at the end of the monsoon season in September up to $75 \%$ of the air masses within the Asian monsoon anticyclone were younger than 5 months. In addition, they showed that the emission tracer for India/China (northern India plus southern India plus eastern China) is a good proxy for the location and shape of Asian monsoon anticyclone using pattern correlations with potential vorticity (PV), and MLS $\mathrm{O}_{3}$ and $\mathrm{CO}$ measurements. Therefore, the emission tracer for India/China is very well suited for analyzing transport of air masses from the Asian monsoon anticyclone into the northern lower stratosphere. The emission tracer for southeast Asia also contributes to the composition of the Asian monsoon but is additionally found in air masses circulating around the outer edge of the Asian monsoon anticyclone at levels of potential temperature of around $380 \mathrm{~K}$.

The most important regions for our study are India/China (equivalent to northern India (NIN) plus southern India (SIN) plus eastern China (ECH)), southeast Asia (SEA), and the tropical Pacific Ocean (TPO). The sum of all model boundary layer tracers $\left(\Omega=\sum_{i=1}^{n} \Omega_{i}\right)$ without contributions from India/China, southeast Asia, and the tropical Pacific Ocean is
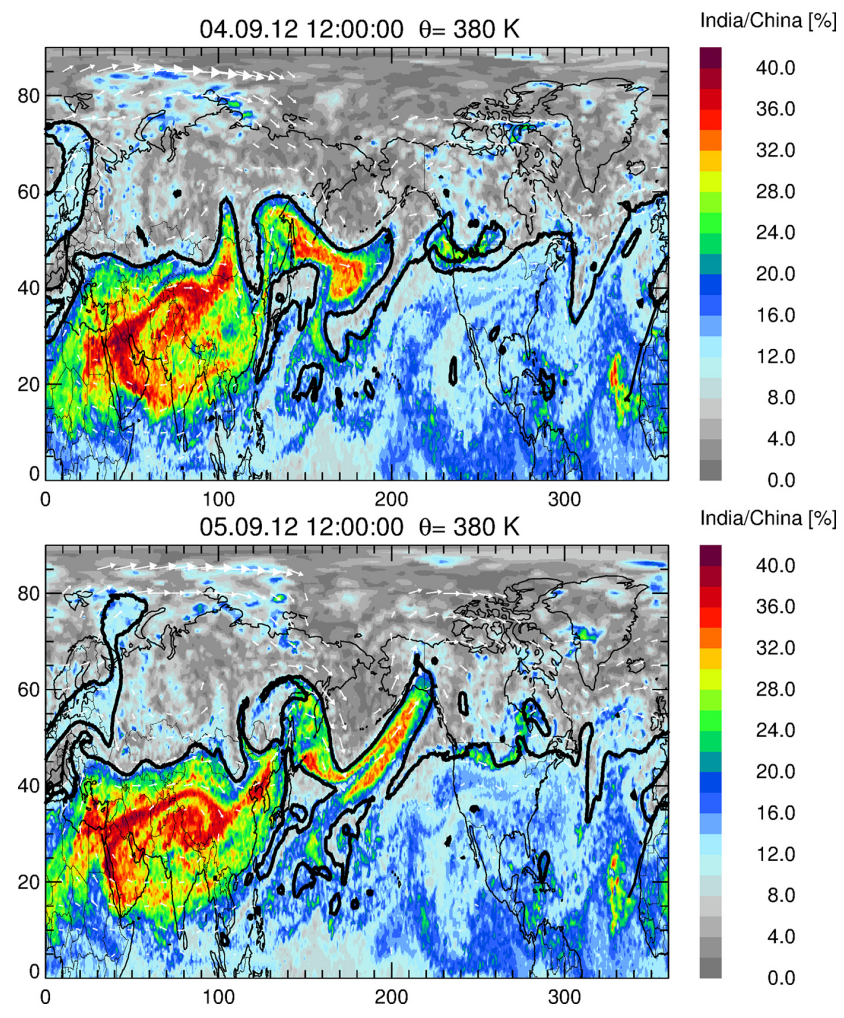

Figure 2. Horizontal distribution of the fraction of air originating in India/China (here the sum of emissions from northern India, southern India, and eastern China) at $380 \mathrm{~K}$ potential temperature on 4 (top) and 5 (bottom) September 2012. The horizontal winds are indicated by white arrows. The 7.2 PVU surface is shown as a thick black line, indicating the climatological isentropic transport barrier at $380 \mathrm{~K}$ in September (Kunz et al., 2015).

summarized in one emission tracer referred to as "the residual surface" ( $=\Omega-\mathrm{NIN}-\mathrm{SIN}-\mathrm{ECH}-\mathrm{SEA}-\mathrm{TPO})$.

\section{Results}

\subsection{Eastward eddy shedding and separation of filaments}

We will analyze transport mechanisms and pathways of tropospheric air masses separated by eastward eddy shedding or filaments at the northeastern flank of the Asian monsoon anticyclone into the lower stratosphere over Europe for the 2012 monsoon season.

At the northeastern flank of the Asian monsoon anticyclone, filaments with low PV and enhanced percentages of the emission tracer for India/China were frequently separated from the main anticyclone in 2012, e.g., on 4 and 5 September 2012, as shown in Fig. 2. In addition, eastwardmigrating anticyclones broke off from the main anticyclone several times during summer. A pronounced eddy-shedding event occurred on 20 September 2012 (Vogel et al., 2014). A 

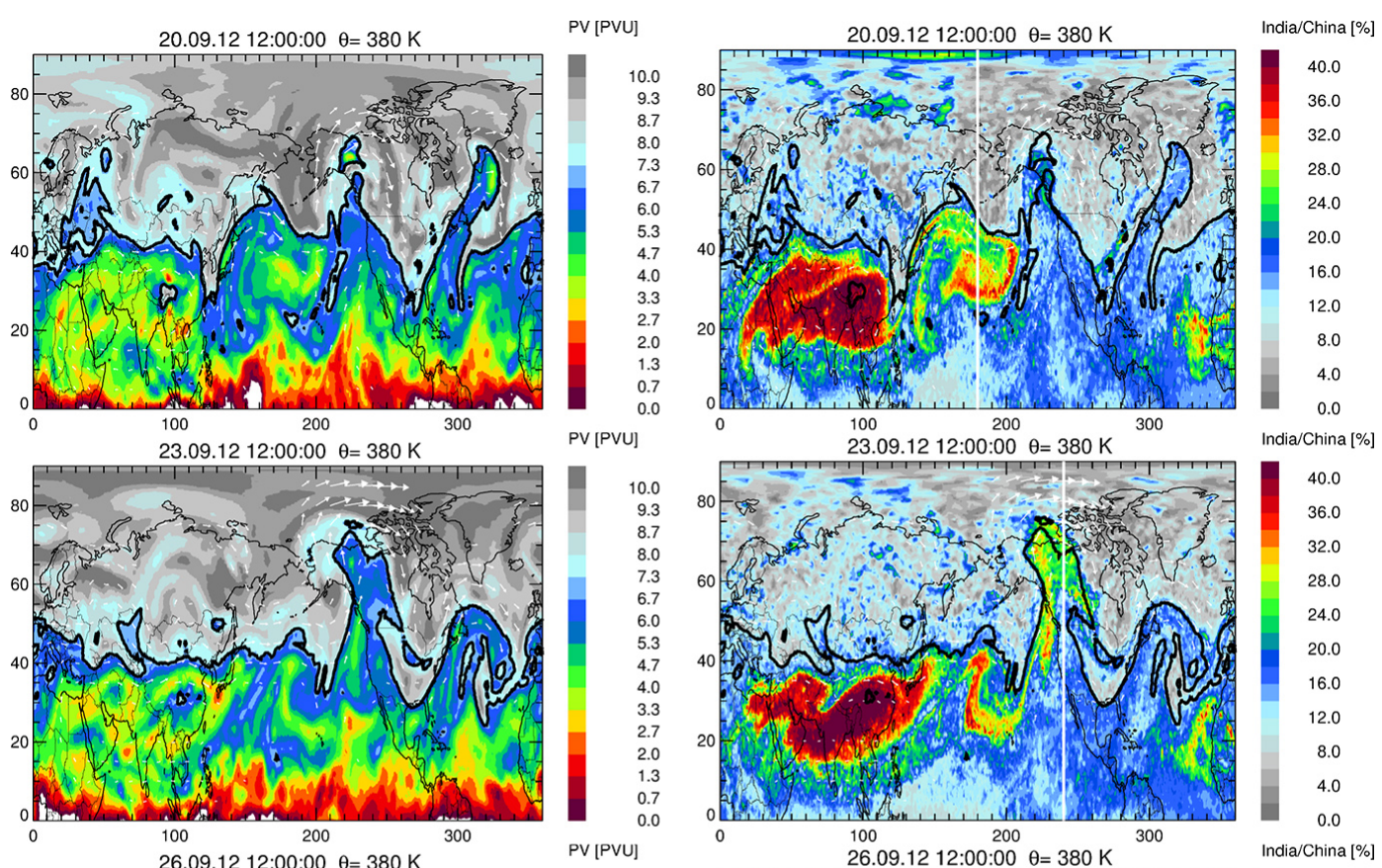

India/China [\%]
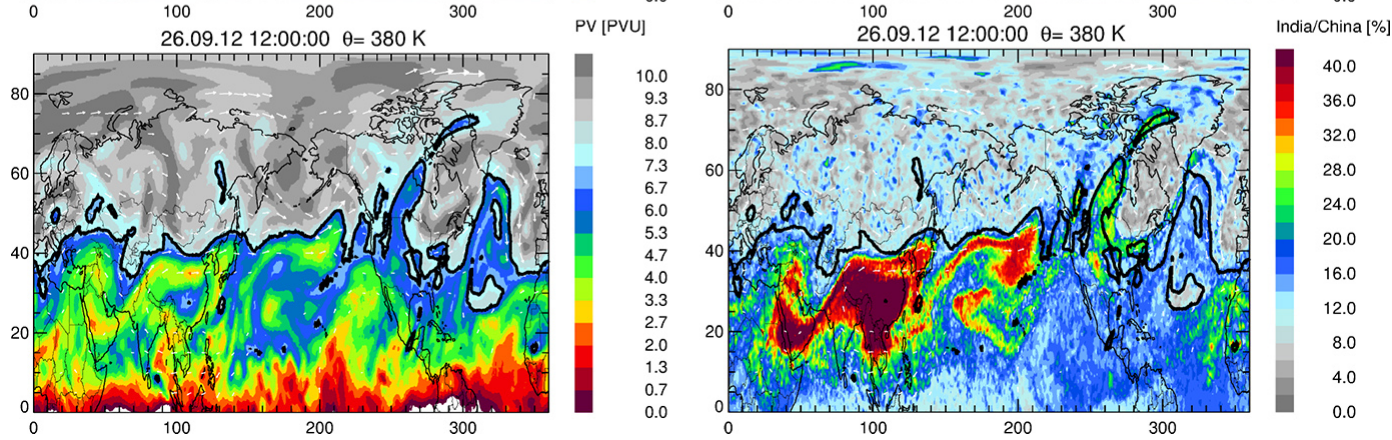

Figure 3. Horizontal distribution of PV (left) and the fraction of air originating in India/China (right) (here the sum of emissions from northern India, southern India, and eastern China) at $380 \mathrm{~K}$ potential temperature on 20, 23, and 26 September 2012. The horizontal winds are indicated by white arrows. The 7.2 PVU surface is shown as a thick black line, indicating the climatological isentropic transport barrier at $380 \mathrm{~K}$ in September (Kunz et al., 2015). The thick white lines at $180^{\circ} \mathrm{E}$ and at $120^{\circ} \mathrm{W}$ mark the position of the vertical curtains shown in Figs. 5 and 6.

second anticyclone $\left(130-210^{\circ} \mathrm{E}\right)$ characterized by low PV separated from the main Asian monsoon anticyclone (10$110^{\circ}$ E) on 20 September 2012, as shown in Fig. 3 (top left). Thereafter, these air masses characterized by low PV were transported to the Pacific Ocean (see Fig. 3, left) at $380 \mathrm{~K}$.

Figure 3 (right column) shows that air masses with enhanced contributions of the emission tracers for India/China and originating from the Asian monsoon anticyclone were transported eastwards within the separated anticyclone. After 20 September 2012, a long filament of air characterized by low PV and enhanced percentages of emission tracers for India/China evolved from the separated anticyclone. On 23 September 2012, this filament was located over North America along a poleward excursion of the subtropical westerly jet. Between 24 and 26 September 2012, these air masses were transported further eastwards over North America and subsequently to the Atlantic Ocean.
A very similar horizontal distribution to that of the emission tracer for India/China is also found for simulated CO (see Fig. 4, left). However, enhanced $\mathrm{CO}$ values are additionally found at $380 \mathrm{~K}$ in the tropics, associated with deep uplift in the tropics outside of the monsoon region to the upper troposphere, in particular over the Maritime Continent (the region between Indian and Pacific oceans) and the western Pacific (see emission tracer for southeast Asia and tropical Pacific Ocean in Appendix A to this paper). Further, the emission tracer for southeast Asia/tropical Pacific Ocean contributes to the composition of the Asian monsoon anticyclone, although to a smaller extent compared to the emission tracer for India/China, as shown in Fig. 4 (right). Contributions from the residual surface (the entire model boundary layer without contributions from India/China, southeast Asia, and the tropical Pacific Ocean; see Sect. 3) are of minor importance (see Sect. 4.2). Note that contribution of air masses 

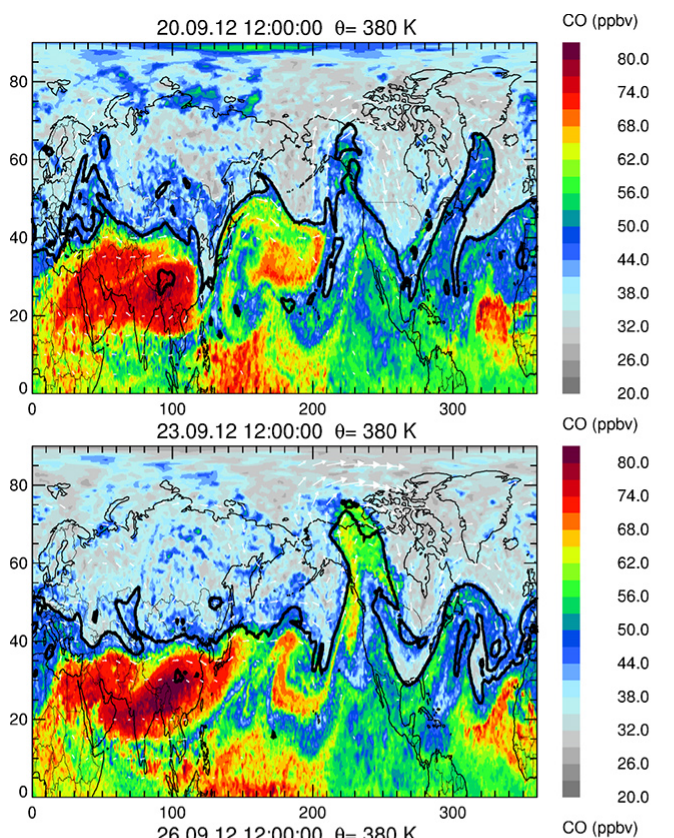

$\mathrm{CO}$ (ppbv)
80.0
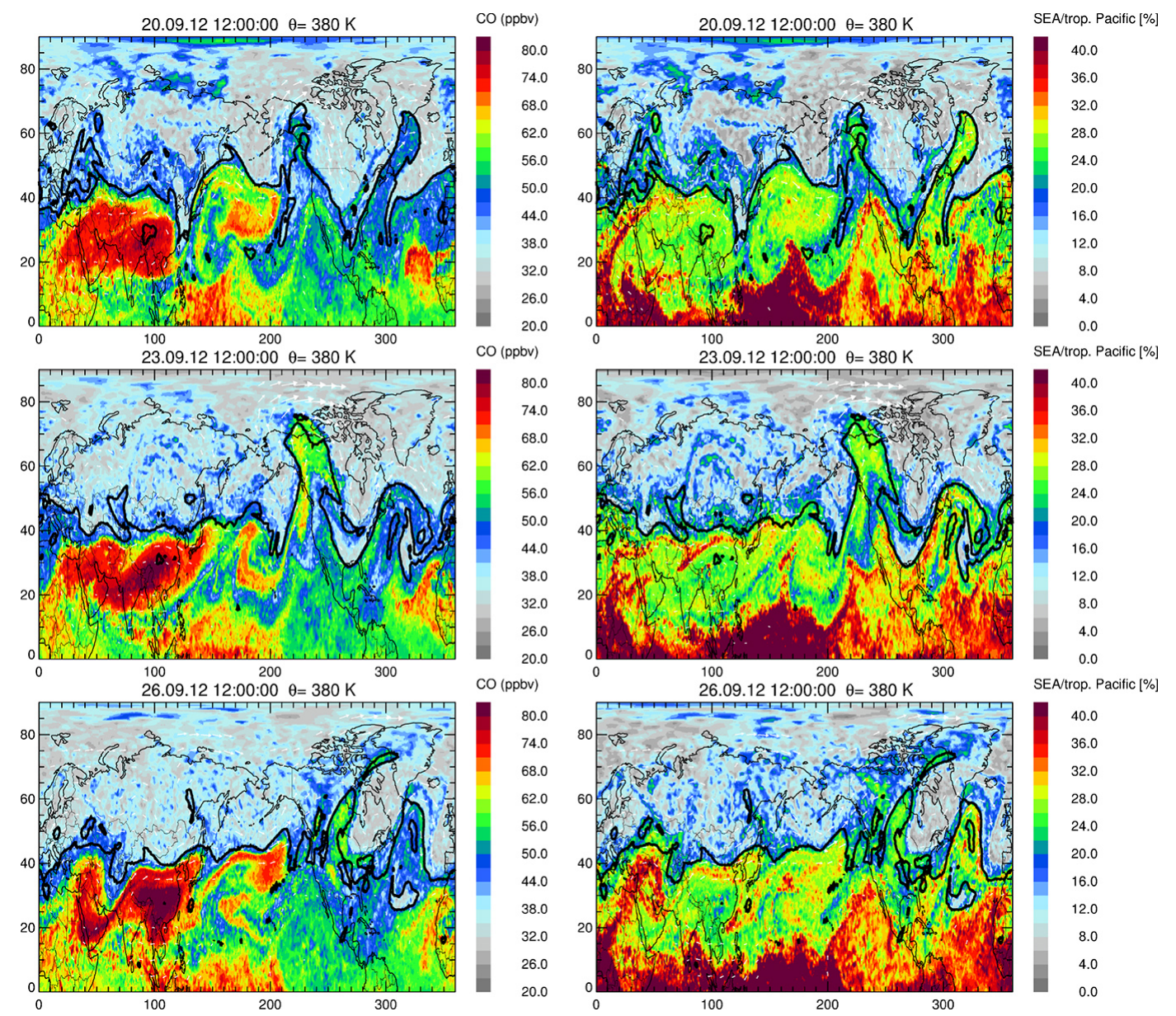

40.0

36.0

32.0

28.0

24.0

20.0

16.0

12.0

8.0

4.0

0.0

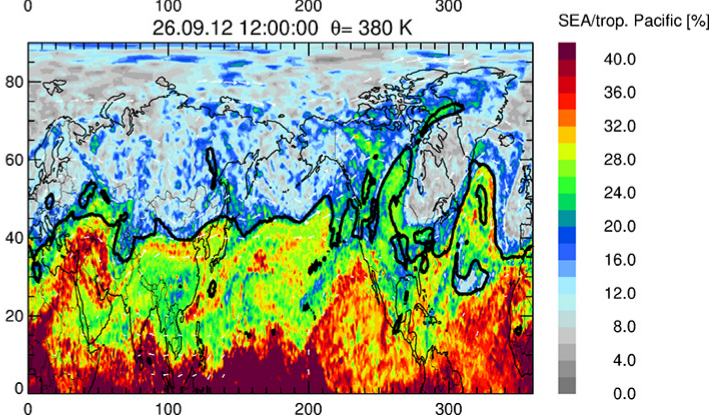

Figure 4. The same as Fig. 3, but for simulated CO (left) and the fraction of air originating in southeast Asia/tropical Pacific Ocean.

originating in the free troposphere and stratosphere (aged air masses) also contribute to the composition of the Asian monsoon anticyclone about $25 \%$ at the end of September 2012 (see Vogel et al., 2015, their Fig. 9).

Maximum percentages for the emission tracer for southeast Asia/tropical Pacific Ocean are found at the edge of the Asian monsoon anticyclone, indicating the transport of these air masses around the outer edge of the Asian monsoon anticyclone outside of a PV-based transport barrier (Ploeger et al., 2015) as discussed by Vogel et al. (2015). Thus, air masses from southeast Asia/tropical Pacific Ocean are found within a widespread area around the anticyclone caused by the large-scale anticyclonic flow in this region acting as a large-scale stirrer. Moreover, large contributions of these emission tracers are found in the tropics associated with deep uplift outside of the monsoon region.

Kunz et al. (2015) derived a climatology of PV streamers (e.g., poleward-moving filaments with low PV originating in the tropics) as indicators of Rossby wave breaking on isentropes between 320 and $500 \mathrm{~K}$ using ERA-Interim reanalyses for the time period from 1979 to 2011 . The 7.2 PVU isoline shown in black in Figs. 3 and 4 represents the isen- tropic transport barrier between the tropics and midlatitudes based on the climatology of the dynamically relevant PV contours derived by Kunz et al. (2015) at $380 \mathrm{~K}$ for the Northern Hemisphere from September to November. Isentropic transport of air masses across the 7.2 PVU isoline indicates exchange between the tropics and extratropics due to wave breaking. On 20 September 2012, at the northern flank of the separated anticyclone, the 7.2 PVU isoline is in the region where strongest gradients of the emission tracers occur, indicating the transport barrier at $380 \mathrm{~K}$ (see Figs. 3 and 4).

If latitude-height cross sections from the separated anticyclone caused by eddy shedding at $180^{\circ} \mathrm{E}$ (Fig. 5) are considered, this shows that air masses within the separated anticyclone $\left(20-40^{\circ} \mathrm{N}\right)$ throughout the troposphere are characterized by high percentages of the emission tracers for India/China (top left). The vertical tracer distribution of the separated anticyclone resembles a bubble that is confined by the subtropical westerly jet in the north $\left(35-55^{\circ} \mathrm{N}\right)$ and by the thermal tropopause at the top. The thermal tropopause is slightly elevated, in a similar manner to the Asian monsoon anticyclone itself. Here, the thermal tropopause acts as a transport barrier for further upward transport from the sep- 

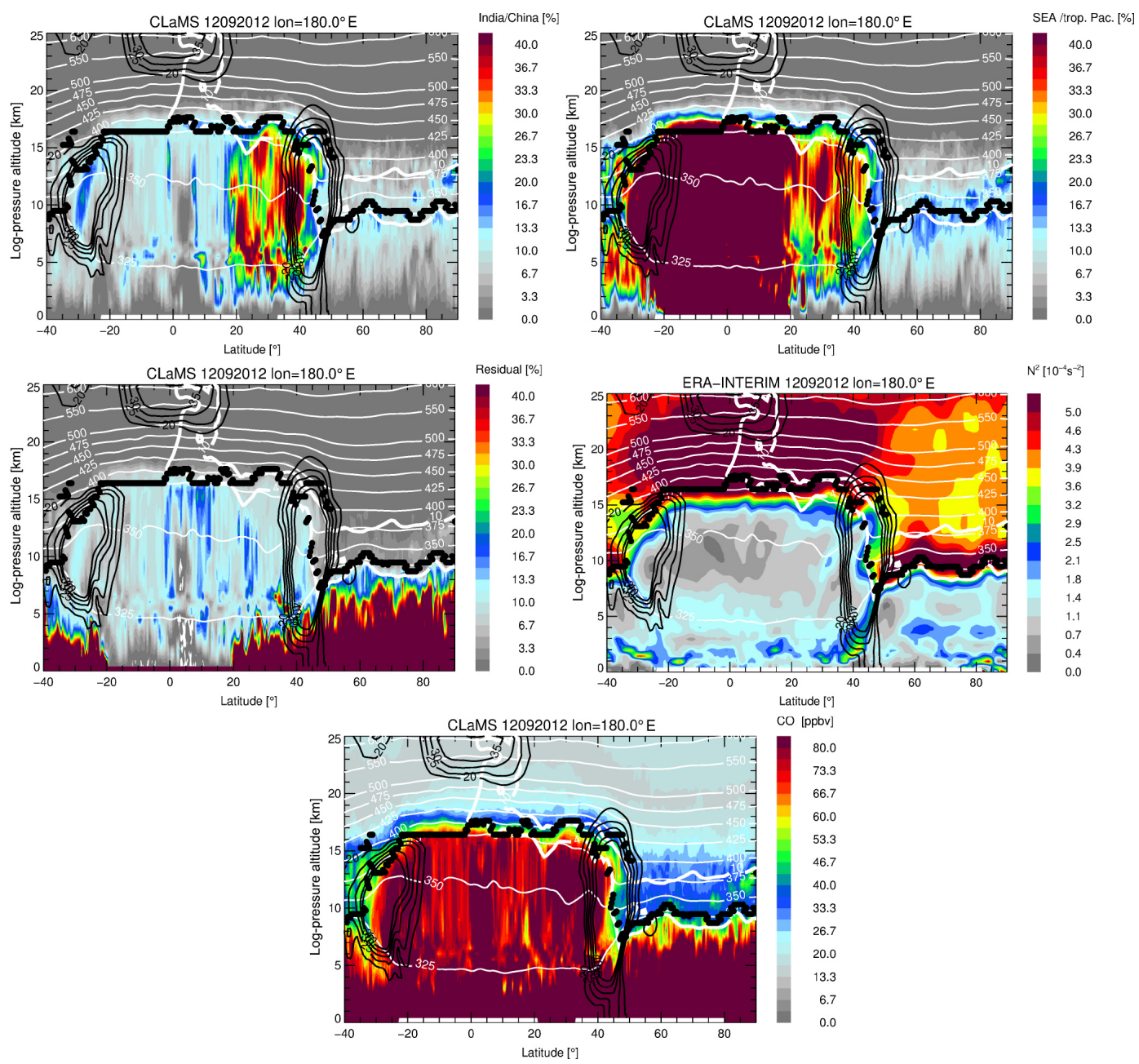

Figure 5. Latitude-height cross sections from $40^{\circ} \mathrm{S}$ to $90^{\circ} \mathrm{N}$ at $180^{\circ} \mathrm{E}$ longitude on 20 September 2012 including the separated anticyclone $\left(\approx 25-45^{\circ} \mathrm{N}\right)$ caused by an eddy-shedding event for the fraction of air originating in India/China (top left), the fraction of air originating in southeast Asia/tropical Pacific Ocean (top right), the fraction of air originating in the residual surface (bottom left), and buoyancy frequency squared $N^{2}$ (bottom right). The climatological isentropic transport barriers of 4 and $10 \mathrm{PVU}$ at 350 and $400 \mathrm{~K}$, respectively, for September (thick white lines) and thermal tropopause (black dots) are shown. The corresponding levels of potential temperature are marked by thin white lines.

arated anticyclone into the lower stratosphere. The term "tropospheric bubble" is also used to describe the trace gas distribution within the Asian monsoon itself (Pan et al., 2016).

In addition, the isentropic transport barriers of 4 and $10 \mathrm{PVU}$ at 350 and $400 \mathrm{~K}$ (Kunz et al., 2015), respectively, are shown in Fig. 5 (thick white lines) for the Northern Hemisphere for September to November. No significant transport across these PV isolines at the polar edge of the separated anticyclone was found, indicating here that no air mass exchange between stratosphere and troposphere occurred due to Rossby wave breaking.

The latitude-height cross section for the emission tracer for southeast Asia/tropical Pacific Ocean (Fig. 5, top right) also has the structure of a bubble with enhanced percentages. These enhanced contributions of the emission tracer for southeast Asia/tropical Pacific Ocean are clearly separated from the tropics, outside of the monsoon circulation, which shows even higher contributions (up to $40 \%$ ) of these tracers.

Figure 5 (bottom left) shows the emission tracer for the residual surface (the entire model boundary layer without contributions from India/China, southeast Asia, and the tropical Pacific Ocean; see Sect. 3). The contribution of the emission tracer for the residual surface is approximately $10-15 \%$ within the separated anticyclone, indicating that air masses originating in India/China and southeast Asia/tropical Pacific Ocean almost exclusively contribute to the chemical composition of the separated anticyclone.

In general, the troposphere is characterized by weak static stability (buoyancy frequency squared, $N^{2}$ ) in contrast to stratospheric air masses. The latitude-height cross section of 

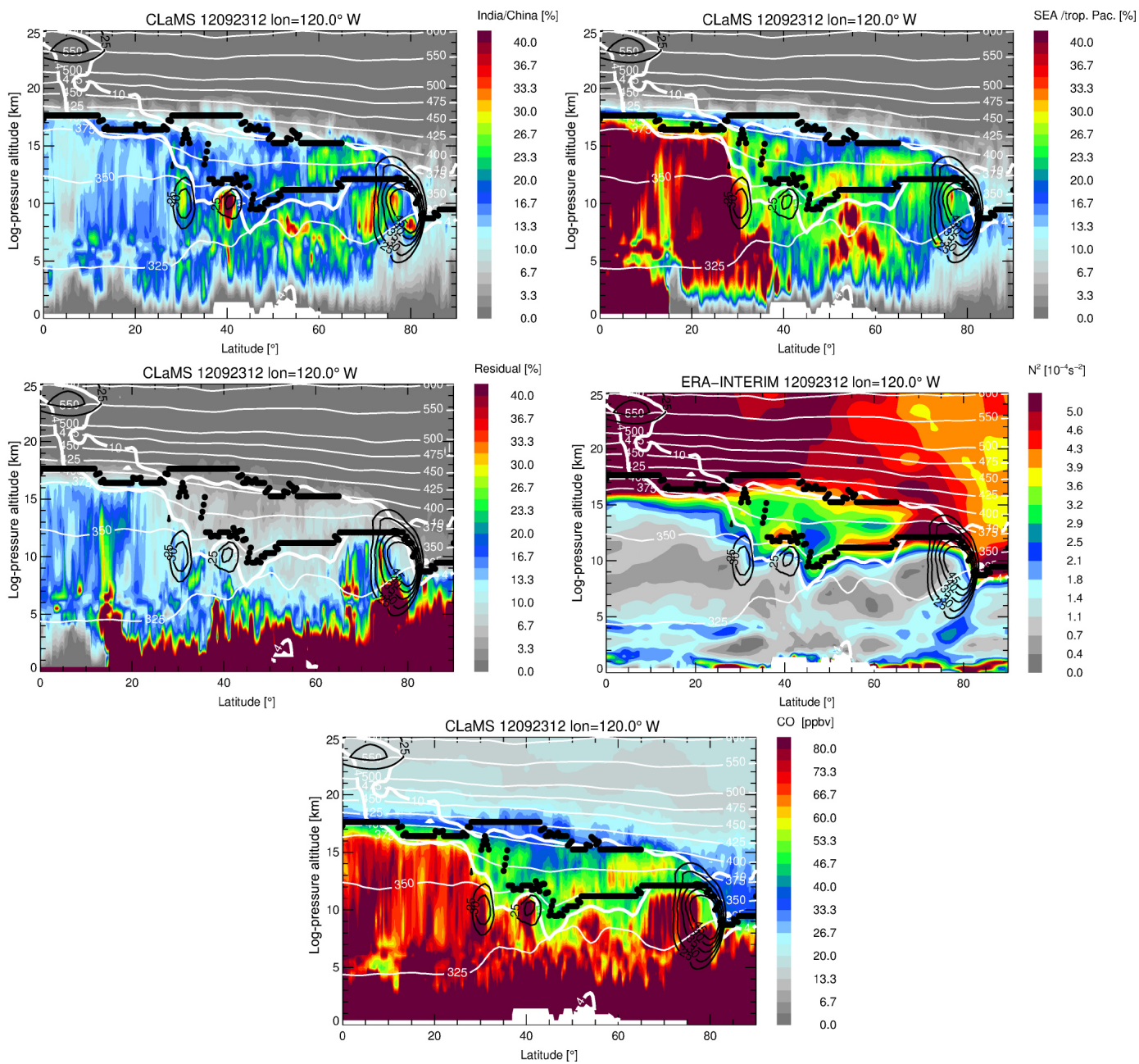

Figure 6. Latitude-height cross sections of the Northern Hemisphere at $120^{\circ} \mathrm{W}$ longitude on 23 September 2012 including a northwarddirected filament of low PV $\left(\approx 35-80^{\circ} \mathrm{N}\right)$ moving along the subtropical jet for the fraction of air originating in India/China (top left), the fraction of air originating in southeast Asia/tropical Pacific Ocean (top right), the fraction of air originating in the residual surface (bottom left), and buoyancy frequency squared $N^{2}$ (bottom right). The climatological isentropic transport barriers of 4 and $10 \mathrm{PVU}$ at 350 and $400 \mathrm{~K}$, respectively, for September (thick white lines) and thermal tropopause (black dots) are shown. The corresponding levels of potential temperature are marked by thin white lines.

$N^{2}$ (Fig. 5, bottom right) shows that air masses within the separated anticyclone are characterized by tropospheric $N^{2}$ values. Our model simulation demonstrates that air masses enclosed in the second anticyclone are still located in the troposphere. The question arises of where exactly air masses from the Asian monsoon anticyclone separated by eddy shedding or large filaments will enter the lower stratosphere, i.e., where exactly they cross the extratropical tropopause.

\subsection{Isentropic transport pathways into the lower stratosphere}

As shown in Figs. 3 and 4 (middle), a long filament of air characterized by low PV and high percentages of emission tracers for India/China and southeast Asia/tropical Pacific Ocean evolved from the separated anticyclone. On 23
September 2012, this filament was located over North America along the subtropical westerly jet. At $380 \mathrm{~K}$, enhanced contributions of the emission tracer from India/China were also found north of the 7.2 PVU barrier, indicating transport from the troposphere into the stratosphere according to the definition by Kunz et al. (2015).

An latitude-height cross sections at $120^{\circ} \mathrm{W}$ on 23 September 2012 cutting the filament over northern America is shown in Fig. 6. A double thermal tropopause $\left(30-65^{\circ} \mathrm{N}\right)$ is found along the filament (see black dots in Fig. 6) which encloses a tropospheric intrusion centered around $370 \mathrm{~K}$ with a vertical extension of up to $50 \mathrm{~K}$. Air masses associated with a tropospheric intrusion, namely tropospheric air masses intruding poleward into the lower stratosphere, are characterized by lower values of ozone, PV, $N^{2}$, and higher values of wa- 


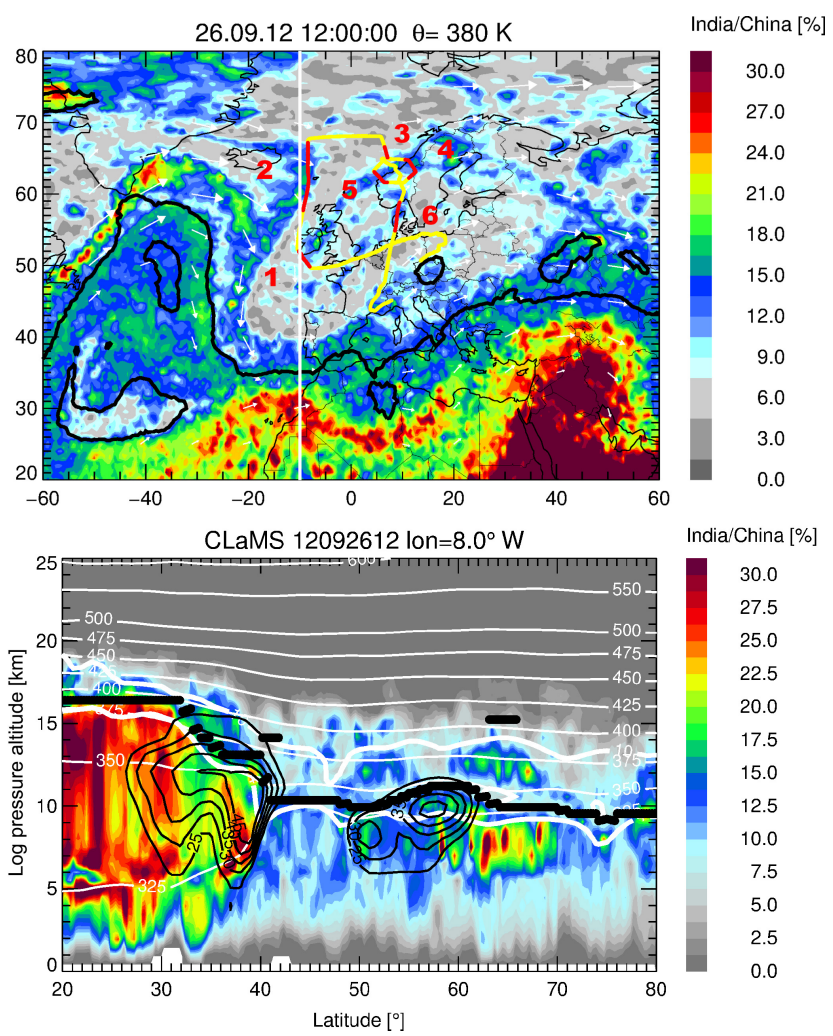

Figure 7. Horizontal (top) cross section of the fraction of air originating in India/China over Europe on 26 September 2012. The flight path transferred to noontime of the TACTS/ESMVal flight is shown as a yellow line. Segments of the flight in the lower stratosphere with enhanced measured $\mathrm{CO}, \mathrm{CH}_{4}$, and $\mathrm{H}_{2} \mathrm{O}$, and reduced $\mathrm{O}_{3}$ compared to the stratospheric background are highlighted in red and numbered for clarification (the same numbers are used in Fig. 9) The climatological isentropic transport barrier of 7.2 PVU at $380 \mathrm{~K}$ is shown as a thick black line. The thick white line marks the position of the vertical (bottom) cross section at $8^{\circ} \mathrm{W}$ longitude, which is similar to the cross sections shown in Figs. 5 and 6.

ter vapor and $\mathrm{CO}$ compared to the stratospheric background (Pan et al., 2009; Homeyer et al., 2011; Vogel et al., 2011b; Ploeger et al., 2013). Indeed, the air mass in the tropospheric intrusion shows low $N^{2}$ value (Fig. 6, middle right) and enhanced simulated CO (Fig. 6, bottom). As an illustration, the 4 PVU and 10 PVU isolines are shown as thick white lines in Fig. 6, indicating the climatological isentropic transport barrier at 350 and $400 \mathrm{~K}$, respectively, for the Northern Hemisphere for September (Kunz et al., 2015).

Enhanced percentages of the emission tracers for India/China (up to $\approx 30 \%$ ) and southeast Asia/tropical Pacific Ocean (up to $\approx 33 \%$ ) are found between the double tropopauses (see Fig. 6, top) compared to the stratospheric background. This demonstrates the horizontal isentropic transport of young tropospheric air masses from the filament into the lower stratosphere. The impact of the emission tracer of the residual surface is less than $10 \%$, indicating

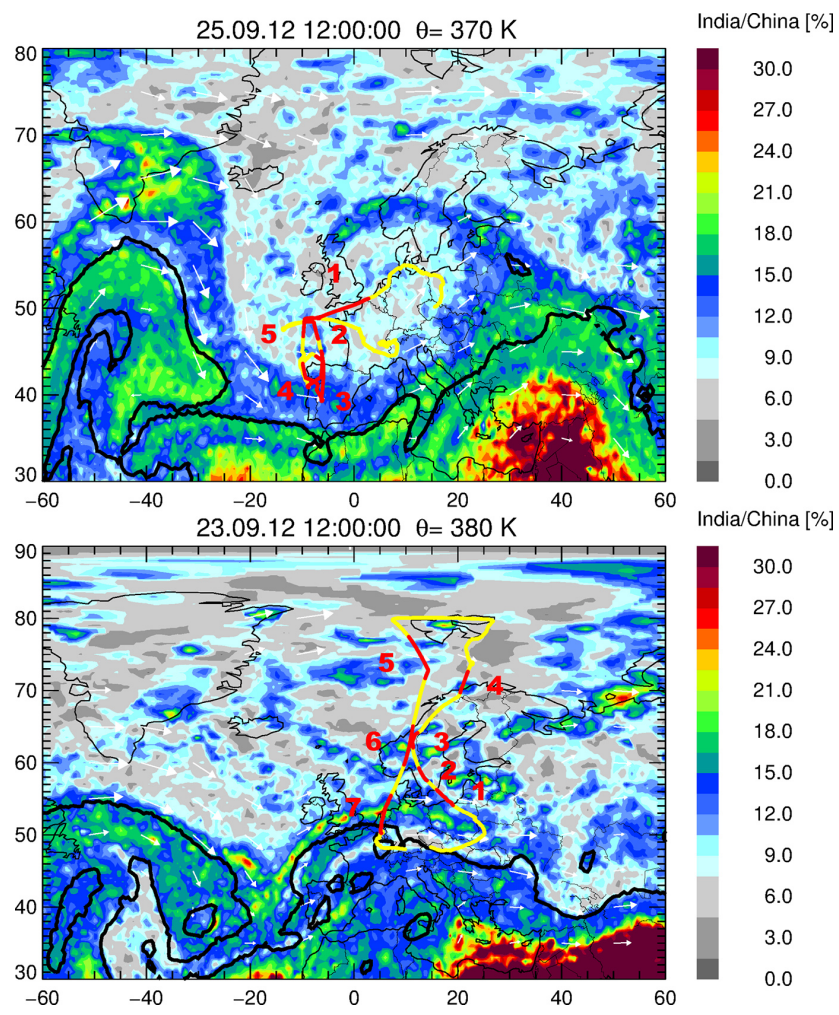

Figure 8. Horizontal cross section of the fraction of air originating in India/China over Europe on 25 September at $370 \mathrm{~K}$ (top) and on 23 September 2012 at $380 \mathrm{~K}$ (bottom). The flight paths transferred to noontime for the TACTS/ESMVal flights 2012 over northern Europe are marked as yellow lines. Segments of the flight in the lower stratosphere with enhanced measured $\mathrm{CO}, \mathrm{CH}_{4}$, and $\mathrm{H}_{2} \mathrm{O}$, and reduced $\mathrm{O}_{3}$ compared to the stratospheric background are highlighted in red and numbered for clarification (the same numbers are used in Figs. 10 and 11). The climatological isentropic transport barriers of 6.0 PVU (at $370 \mathrm{~K}$ ) and 7.2 PVU (at $380 \mathrm{~K}$ ) are shown as thick black lines.

a minor influence of young air masses originating in other regions of the Earth's surface on the tropospheric intrusion (see Fig. 6 middle left). Thus, the transport of tropospheric air masses from the troposphere into the lower stratosphere occurs in the region between the double tropopauses. Previous studies also found intrusions of tropospheric air into the lower stratosphere associated with extratropical double tropopauses (e.g., Pan et al., 2009; Homeyer et al., 2011; Vogel et al., 2011b; Schwartz et al., 2015; Wu and Lü, 2015). Further, it was shown that double tropopauses are frequently associated with Rossby wave breaking events along the subtropical jet (e.g., Vaughan and Timmis, 1998; Castanheira and Gimeno, 2011; Ungermann et al., 2013; Homeyer and Bowman, 2013; Homeyer et al., 2014).

Consequently, thin filaments with enhanced contributions of emission tracers for India/China (also for southeast Asia/tropical Pacific Ocean not shown here) are found on the polar side of the 7.2 PVU isoline, representing the climato- 


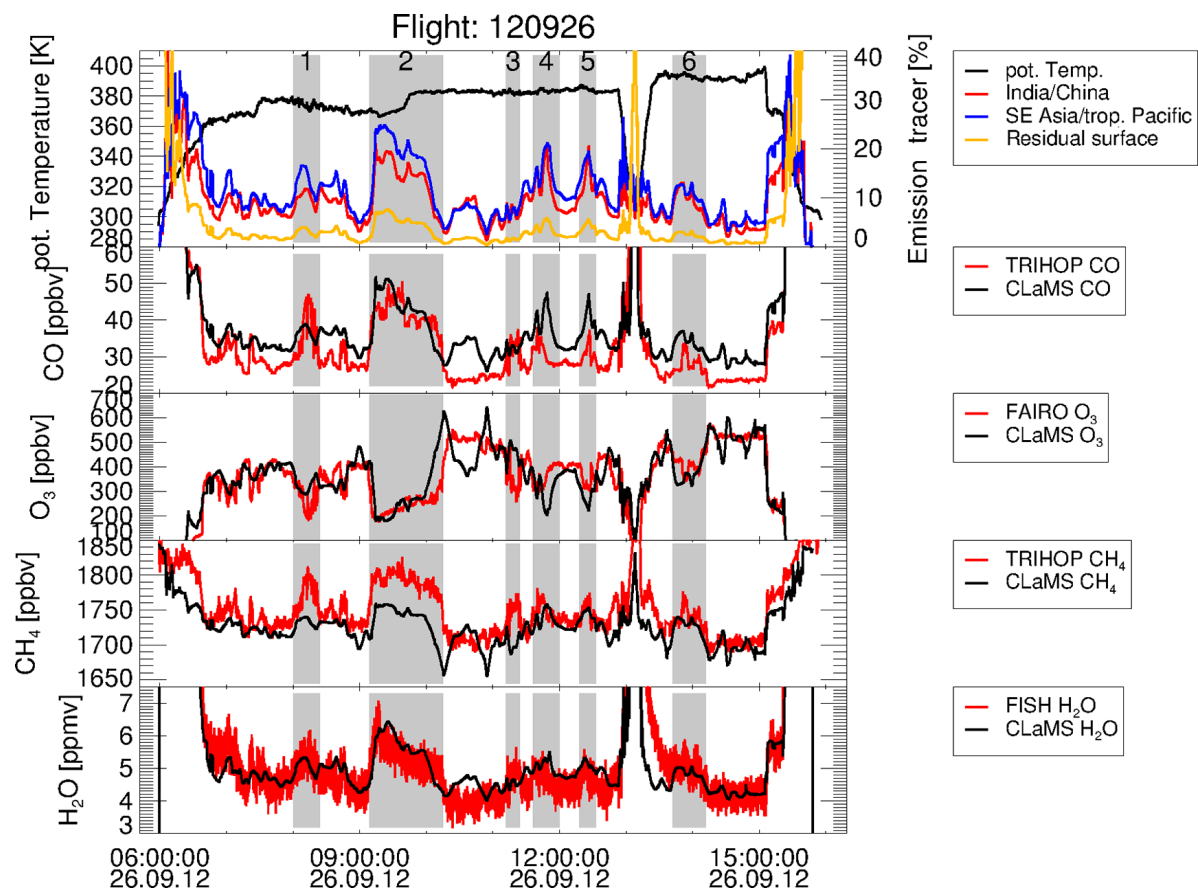

Figure 9. Top panel: time evolution (given in UT time) of potential temperature, the fraction of air originating in India/China, southeast Asia/tropical Pacific and of the residual surface (sum of all other emission tracers covering the entire Earth's surface) simulated with CLaMS for the flight on 26 September 2012. Middle and lower panel: $\mathrm{CO}, \mathrm{O}_{3}, \mathrm{CH}_{4}$, and $\mathrm{H}_{2} \mathrm{O}$ simulations and measurements. Segments of the flight in the lower stratosphere with enhanced measured $\mathrm{CO}, \mathrm{CH}_{4}$, and $\mathrm{H}_{2} \mathrm{O}$, and reduced $\mathrm{O}_{3}$ compared to the stratospheric background are highlighted in gray and numbered for clarification.

logical isentropic transport barrier at $380 \mathrm{~K}$ in September and October 2012 (see Fig. 7, top, thick black line). These small filaments in the lower stratosphere with enhanced percentages of emission tracers for India/China reached the flight path (red line) of the TACTS/ESMVal flight on 26 September 2012 over northern Europe. An latitude-height cross sections at $8^{\circ} \mathrm{W}$ on 26 September 2012 (marked as a thick white line in Fig. 7, top) cross a filament with enhanced contributions of the emission tracers for India/China at $380 \mathrm{~K}$ between 60 and $70^{\circ} \mathrm{N}$ (Fig. 7, bottom). This filament is clearly found above the first thermal tropopause (black dots) within the lower stratosphere associated with a double tropopause.

Similar filaments within the lower stratosphere were also measured in the flight path of the TACTS/ESMVal flights on 23 and 25 September 2012 (Fig. 8). Subsequently, these filaments were mixed with the stratospheric background and dissipated in the lower stratosphere over time.

\subsection{Comparison with TACTS/ESMVal measurements}

Above, in Sect. 4.1 and 4.2, we considered CLaMS simulations using artificial emission tracers to show that air masses originating in Asia and in the tropical Pacific affected the chemical composition of the lower stratosphere over northern Europe in September 2012. In this section, we compare results of the three-dimensional CLaMS simulation of $\mathrm{CO}$,
$\mathrm{O}_{3}, \mathrm{CH}_{4}$, and $\mathrm{H}_{2} \mathrm{O}$ with in situ measurements of three flights on 23, 25, and 26 September 2012 over Europe during the TACTS/ESMVal campaign. The CLaMS results are compared with the in situ measurements along the flight path by interpolation in time and space. The interpolation method is described in detail in Appendix B.

In Figs. 9-11, CLaMS results are presented interpolated along the flight path for each of the three flights. Also shown are the contributions of CLaMS emission tracers for India/China, southeast Asia/tropical Pacific Ocean, and the residual surface interpolated along the flight path (see Figs. 9-11, top). Further, measured $\mathrm{CO}, \mathrm{O}_{3}, \mathrm{CH}_{4}$, and $\mathrm{H}_{2} \mathrm{O}$ mixing ratios are compared with the CLaMS results. Those parts of the flights in the lower stratosphere characterized by enhanced values of measured $\mathrm{CO}, \mathrm{CH}_{4}$, and $\mathrm{H}_{2} \mathrm{O}$, and simultaneously reduced $\mathrm{O}_{3}$ compared to the stratospheric background are highlighted in gray and are numbered for each flight. The same flight segments are shown in red in Figs. 7 and 8 and are also labeled by numbers.

In general, during all three flights, air masses in the lower stratosphere over Europe are affected by boundary emissions from India/China and southeast Asia/tropical Pacific Ocean. Contributions of up to $\approx 20-30 \%$ are found for emission tracers for India/China and southeast Asia/tropical Pacific Ocean. In contrast, the contribution of the emission tracers for the residual surface is below $7 \%$ in the lower strato- 


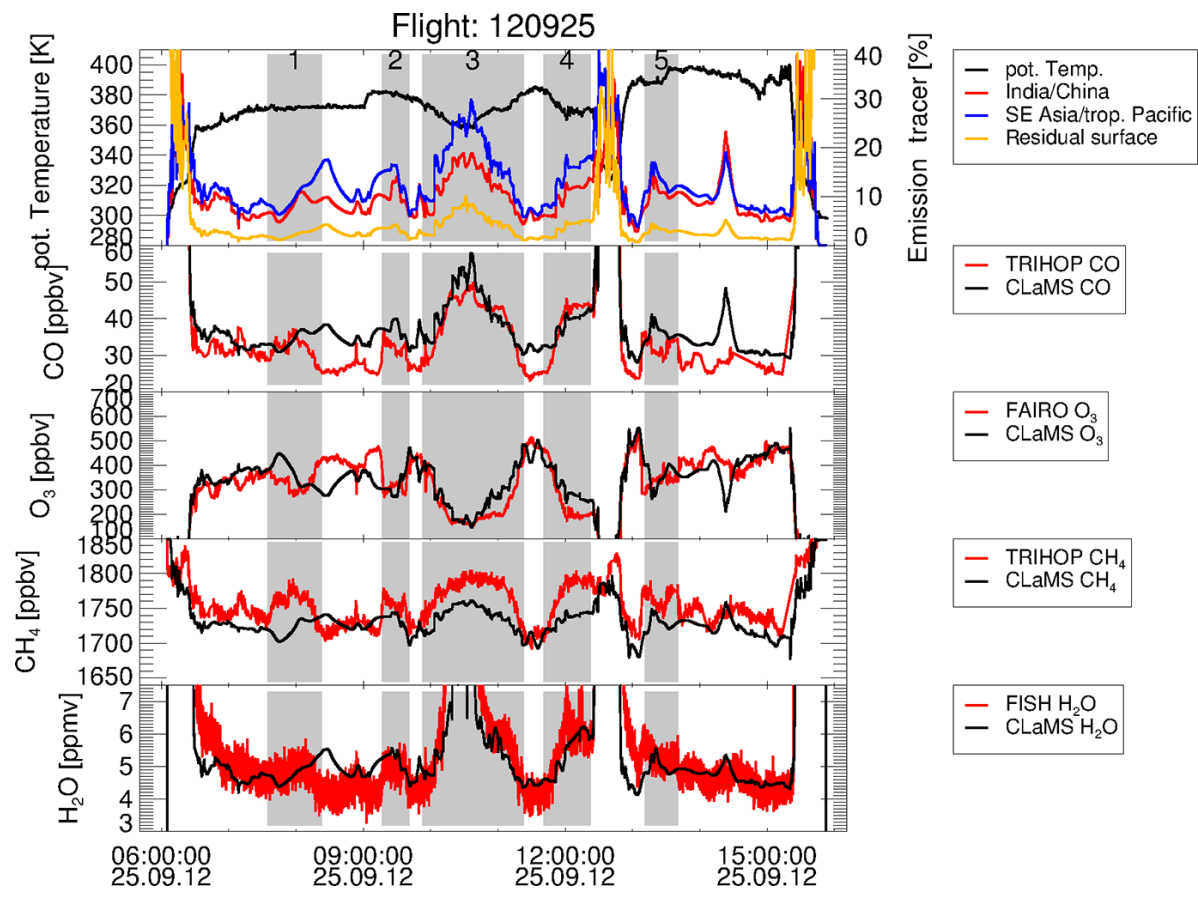

Figure 10. The same as Fig. 9, but for the flight on 25 September 2012.

sphere. Higher contributions are only found in parts of the flight in the troposphere, e.g., during take off, landing, or a flight pattern with a steep decent down into the troposphere followed by a steep ascent back into the lower stratosphere, referred to as a "dive" (see Fig. 9 (top) shortly after 13:00 UTC and Fig. 11 (top) around 10:00 UTC).

In regions with enhanced values of measured $\mathrm{CO}, \mathrm{CH}_{4}$, and $\mathrm{H}_{2} \mathrm{O}$, and reduced $\mathrm{O}_{3}$, generally also the contributions of the emission tracers for India/China and southeast Asia/tropical Pacific Ocean simulated with CLaMS are enhanced (shown in gray). Further, good overall agreement is found between measurements of $\mathrm{CO}, \mathrm{H}_{2} \mathrm{O}, \mathrm{O}_{3}$, and CLaMS simulations. The simulated values of $\mathrm{CH}_{4}$ are in general lower than the measurements (up to $\approx 50 \mathrm{ppbv}$ ). However, the simulated $\mathrm{CH}_{4}$ signatures correspond to the measurements. Differences between model and measurements are most likely caused by uncertainties in the lower boundary conditions of CLaMS (see Sect. 3) which do not include individual emission events of $\mathrm{CO}$ or $\mathrm{CH}_{4}$ (see Pommrich et al., 2014).

In the following, we discuss the individual signatures of tropospheric air notable in the measurements. These signatures are shown in gray and for clarification, are numbered for each flight (see Figs. 9-11, top).

On 26 September 2012 (see Fig. 9, top), a very pronounced signature of tropospheric air in the lower stratosphere was found between 09:05 and 10:17 UTC (no. 2). Here, the contributions of the emission tracer for India/China and southeast Asia/tropical Pacific Ocean amount to as much as 20 and $23 \%$, respectively (up to $5 \%$ from the residual surface).
Thus, the sum of all emission tracers for the model boundary layer is roughly $48 \%$. The remaining $52 \%$ of the composition of the lower stratosphere in this region comes from aged air masses originating in the free troposphere and the stratosphere at the beginning of the CLaMS simulation on 1 May 2012.

This is consistent with backward trajectory calculations reported by Vogel et al. (2014) showing that these air masses are affected by the Asian monsoon anticyclone. Some of the trajectories $(2 \%)$ originated in the West Pacific and experienced very rapid uplift in typhoon Bolaven on 24-25 August 2012. The air masses uplifted by typhoon Bolaven were transported from the Earth's surface over the West Pacific within 5 weeks to the lower stratosphere over Europe (Vogel et al., 2014).

Further, on 26 September 2012 (see Fig. 9, top), a second pronounced signature of tropospheric air (measured $\mathrm{CO}$, $\mathrm{O}_{3}, \mathrm{CH}_{4}$, and $\mathrm{H}_{2} \mathrm{O}$ values are of similar magnitude as for no. 2) was found in the lower stratosphere between 08:05 and 10:23 UTC (no. 1). Also here, the contributions of the emission tracers for India/China and southeast Asia/tropical Pacific Ocean are enhanced by up to 10 and $15 \%$, respectively. The 60 -day backward trajectories calculated by Vogel et al. (2014) show that some of these trajectories also originate in the West Pacific region in typhoon Haikui on 2-3 August 2012. However, these trajectories took longer $(\approx 8$ weeks) to reach northern Europe from their origin in the West Pacific.

During the second part of the flight on 26 September 2012 (see Fig. 9, top), further signatures of tropospheric air 


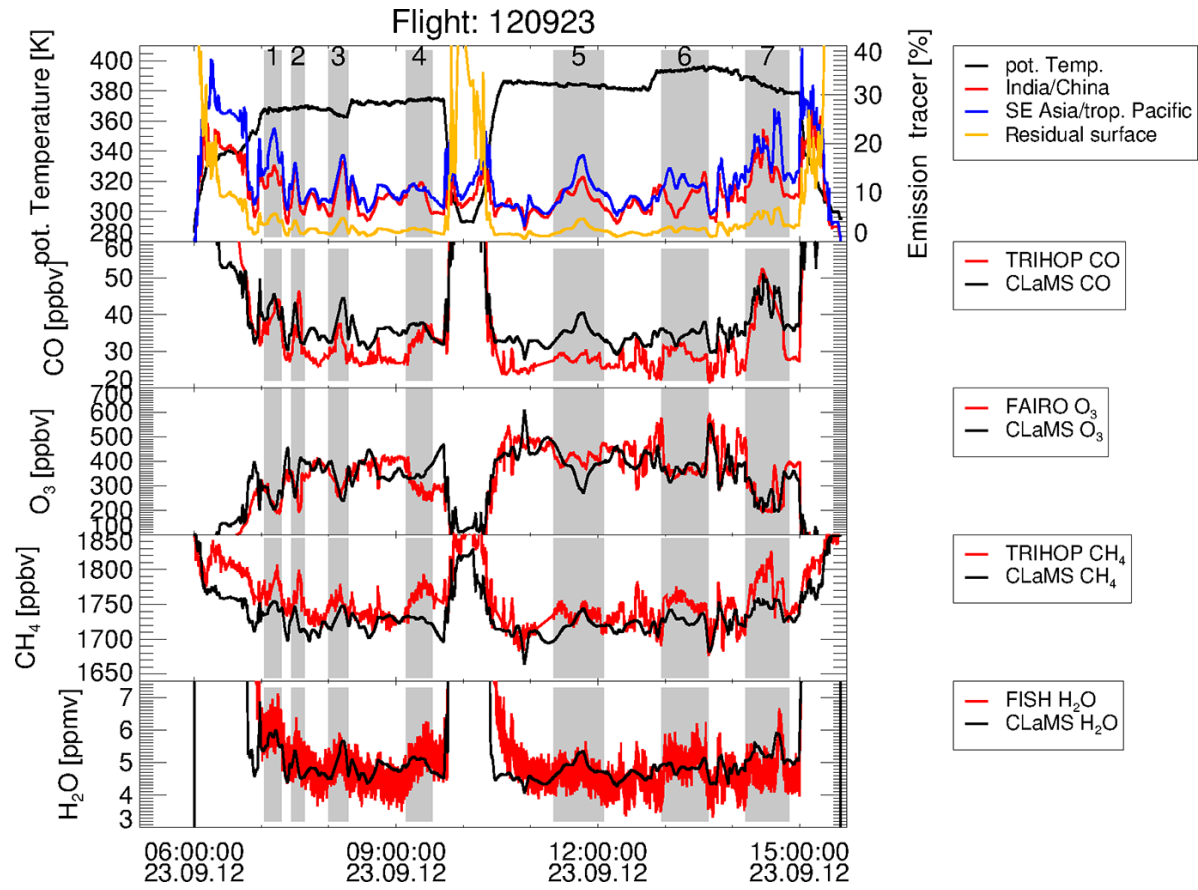

Figure 11. The same as Fig. 9, but for the flight on 23 September 2012.

were measured during the flight (nos. 3-6). Also here, enhanced percentages of the emission tracers for India/China and southeast Asia/tropical Pacific Ocean up to $18 \%$ are simulated, except for region no. 3 , which marks a tropospheric signature only found in the measurements.

During the flights on 25 and 23 September 2012 (see Figs. 10 and 11) several lower tropospheric signatures were also found in the lower stratosphere. Also here, measured tropospheric signals agree in general with the results of the CLaMS model. The results of all these flights confirm that air masses with enhanced amounts of tropospheric trace gases measured in the lower stratosphere over northern Europe originated in boundary source regions in India/China and southeast Asia/tropical Pacific Ocean. Our simulations, in agreement with measurements, show that the amount of water vapor and pollution in the lower stratosphere was enhanced in the Northern Hemisphere in September 2012 associated with both the dynamics of the Asian monsoon anticyclone and the transport of air masses from both Asia and the tropical Pacific along the subtropical jet.

\subsection{Impact from Asian boundary source regions on extratropical lower stratosphere}

\subsubsection{Transport pathways into the lower stratosphere}

In the previous sections, the long-range transport pathway from the Asian monsoon anticyclone into the northern extratropical lower stratosphere was discussed using a case study. Here, the impact of this horizontal transport on the compo- sition of the extratropical lower stratosphere is calculated. Fig. 12 shows the horizontal distribution at $380 \mathrm{~K}$ of mean values of the emission tracer for India/China for July, August, and September 2012. Figures 10 and 11 show that also air masses originating in southeast Asia and in the tropical Pacific contribute to the composition of the lower stratosphere over northern Europe. The horizontal distribution of the emission tracers of southeast Asia and the tropical Pacific at $380 \mathrm{~K}$ from July to September 2012 are shown and discussed in Appendix A to this paper.

In Fig. 12, the temporal evolution of the long-range transport pathway from the region of the Asian monsoon anticyclone into the extratropical lower stratosphere is evident. The frequent separation of air masses at the northeast flank of the Asian monsoon anticyclone and subsequent eastward transport along the subtropical jet is the most important mechanism for long-range transport into the lower northern stratosphere. This long-range transport pathway is most pronounced in September 2012 when the strong eddy-shedding event took place, as discussed in Sect. 4.1. In summer 2012, two main horizontal transport pathways of air masses from the Asian monsoon anticyclone evolved with large amounts of the emission tracer for India/China being transported into the TTL (see Fig. 12d):

1. northeastwards along the subtropical jet (eastward eddy shedding and separations of filaments), and the subsequent transport most likely by Rossby wave breaking events into the lower northern hemispheric stratosphere, and 


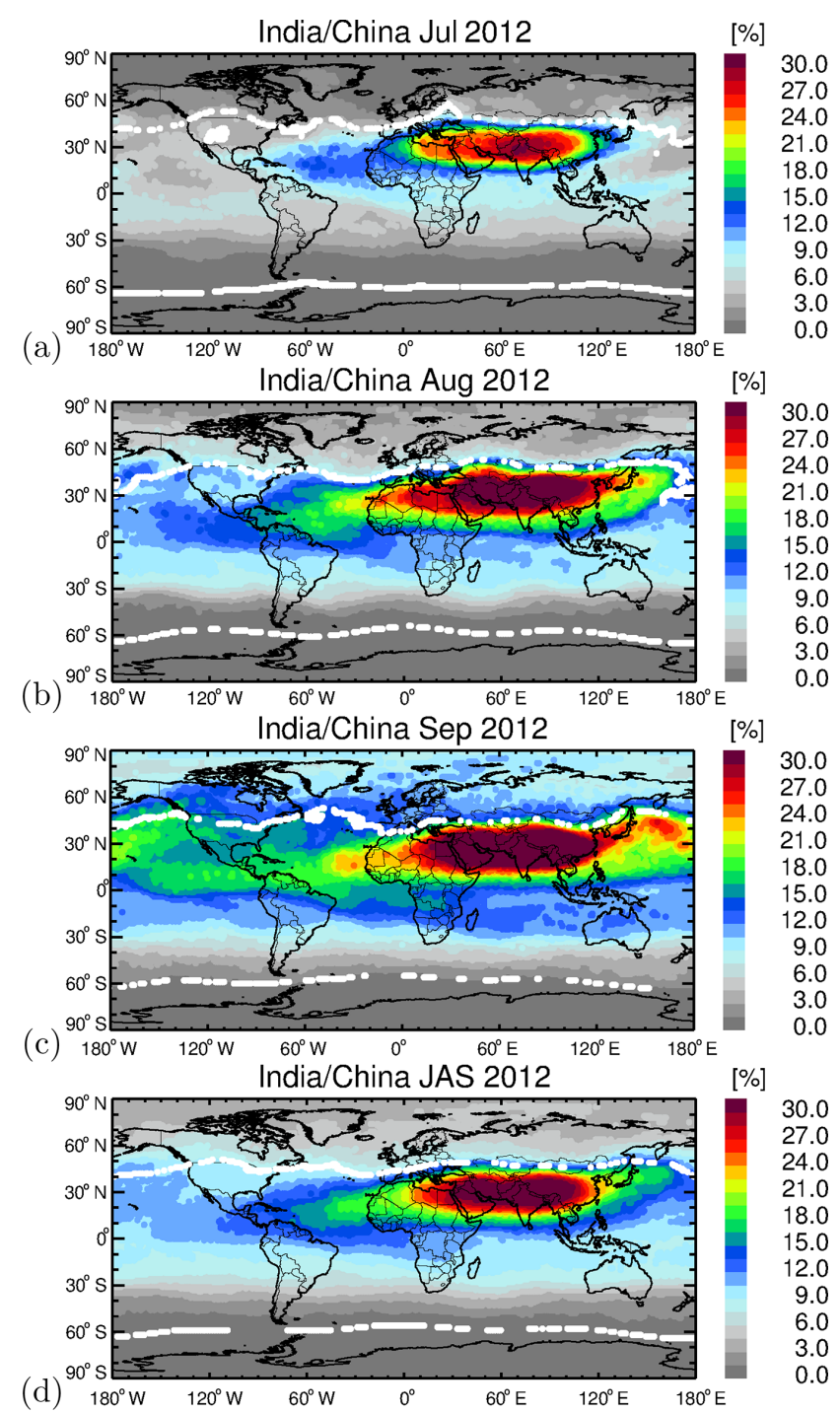

Figure 12. Mean values of the contribution of the emission tracer for India/China at $380 \mathrm{~K}$ in July (a), August (b), and September (c) 2012. Panel (d) shows mean values for India/China for July, August, and September 2012. The climatological isentropic transport barriers of 7.2 PVU (Northern Hemisphere) and -11.5 PVU (Southern Hemisphere) at $380 \mathrm{~K}$ are shown as thick white dots.

2. southwestwards into the tropics (westward eddy shedding) and subsequent mixing within the TTL.

Transport from the Asian monsoon anticyclone both to the east and to the west yields an increase of fresh emissions from India/China within the TTL at $380 \mathrm{~K}$ in summer and autumn 2012. Finally, Fig. 12 shows that transport from air masses originating in the Asian monsoon anticyclone into the lower stratosphere takes place most frequently over the Pacific and Atlantic oceans (see Fig. 12c), which is in agreement with findings by Kunz et al. (2015). In our simulation, the horizontal long-range transport pathway along the sub- tropical jet is furthermore found at levels of potential temperature between 340 and $420 \mathrm{~K}$ (not shown here).

Transport of air masses from the Asian monsoon anticyclone southeastwards into the tropics by, for example, westward eddy shedding causes an increase of the contributions of air masses originating in the boundary layer in India/China within the TTL. These air masses could penetrate into the upwelling in the deep branch of the Brewer-Dobson circulation and thus could be transported further up into the stratosphere (e.g., Garny and Randel, 2016).

To demonstrate that both transport pathways are also evident in observations, we analyze global HCFC-22 measurements of the MIPAS instrument onboard the ENVISAT satellite (Chirkov et al., 2016). The production of the ozonedepleting and greenhouse gas HCFC-22 $\left(\mathrm{CHClF}_{2}\right)$ is regulated by the Montreal Protocol and its amendments and adjustments. In accordance with these regulations, in the last few decades in some regions, e.g., in eastern Asia and in the Near East, HCFC-22 has been used as an interim replacement gas for more potent ozone-depleting substances such as CFCs, although it has been phased out in developed countries (Fortems-Cheiney et al., 2013). Because HCFC-22 is emitted in locally restricted regions, in particular in eastern Asia and therefore in the Asian monsoon region, this trace gas is very well suited for studying transport processes in the Asian monsoon anticyclone. The region where HCFC22 emissions occur in eastern Asia overlaps in parts with the emission tracer for India/China in our CLaMS model simulation for 2012.

No MIPAS measurements are available for summer 2012. Therefore, we compare our results with MIPAS measurements for 2008, because MIPAS HCFC-22 measurements have very good coverage in summer 2008 over Asia. For this comparison, we perform a CLaMS model simulation for summer 2008 with the same setup for emission tracers as for the model simulation of 2012 described in Sect. 3. Figure 13a shows mean values of HCFC-22 (Chirkov et al., 2016) measured by MIPAS for July, August, and September (JAS) 2008 at $380 \mathrm{~K}$. To improve the measurement density of HCFC-22, synoptical interpolation of multiple days of measurements is used through CLaMS trajectory calculations. For each day in JAS 2008, trajectories were computed from the time of measurements in a time window of 5 days (i.e., -2 and +2 days) to 12:00 UTC of the selected day. Subsequently, the mean HCFC-22 values are calculated on a $3^{\circ} \times 3^{\circ}$ latitudelongitude grid between 370 and $390 \mathrm{~K}$.

Similar patterns of HCFC-22 and the emission tracer for India/China are found (see Fig. 13) in the region of the Asian monsoon anticyclone in 2008. This indicates that the two horizontal transport pathways from the Asian monsoon anticyclone to the northeast and to the southwest found in our model results for the India/China tracer in 2012 are also apparent in the MIPAS HCFC-22 measurements and CLaMS simulations for 2008 . 


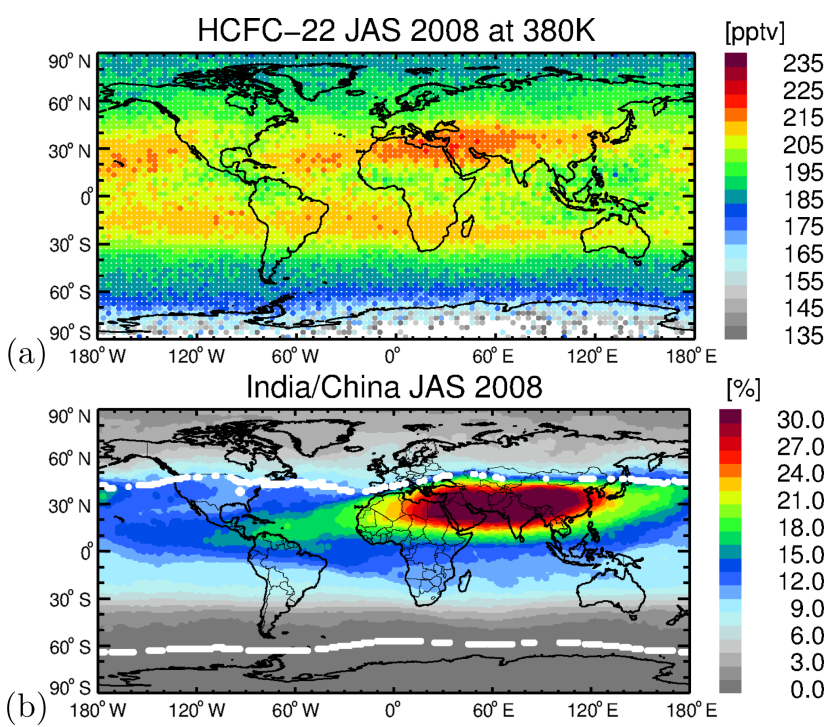

Figure 13. Mean values of HCFC-22 (a) measured by MIPAS for July, August, and September 2008 at $380 \mathrm{~K}$ synoptically interpolated using CLaMS trajectory calculations (for more details, see Sect. 4.4.1). Panel (b) is similar to Fig. 12d, but for the year 2008.

The detailed position of the highest tracer values are somewhat different in 2008 and 2012, probably caused by the interannual variability of the monsoon. Further, enhanced HCFC-22 values are also found in the Southern Hemisphere at the southern edge of the TTL most likely caused by upward transport in the tropics (see patterns of emission tracer for southeast Asia and the tropical Pacific in Appendix A). Nevertheless, MIPAS HCFC-22 measurements demonstrate that the large-scale transport pathways from the Asian monsoon anticyclone at its northeastern flank and at its western flank found by artificial tracers of air mass origin in the CLaMS model are also evident in global satellite measurements.

\subsubsection{Flooding of the extratropical lower stratosphere}

The accumulation of young air masses from Asia since 1 May 2012 in the extratropical lower stratosphere is calculated using the isentropic transport barrier at different levels of potential temperature derived by Kunz et al. (2015), as shown in Fig. 14 and Table 2. To calculate the percentages of different emission tracers within the lower extratropical stratosphere at a certain level of potential temperature, we use the following approach: for each day between 1 May and 31 October 2012, a mean value for each emission tracer of all CLaMS air parcels is calculated for PV values larger (lower) than those at the transport barrier (see Table 2) and for air masses poleward of $30^{\circ} \mathrm{N}\left(30^{\circ} \mathrm{S}\right)$ at a specific isentropic level $(\Theta \pm 0.5 \mathrm{~K})$. At the end of October 2012, the contributions of all boundary emission tracers to the composition of the extratropical northern lower stratosphere are $\approx 44 \%$ at $360 \mathrm{~K}, \approx 35 \%$ at $380 \mathrm{~K}$, and $\approx 23 \%$ at $400 \mathrm{~K}$ with the re-

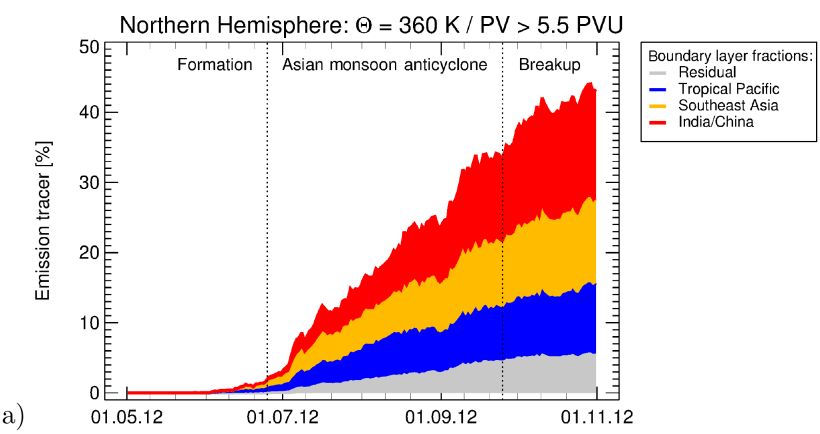

(a)

Northern Hemisphere: $\Theta=380 \mathrm{~K} / \mathrm{PV}>7.2 \mathrm{PVU}$

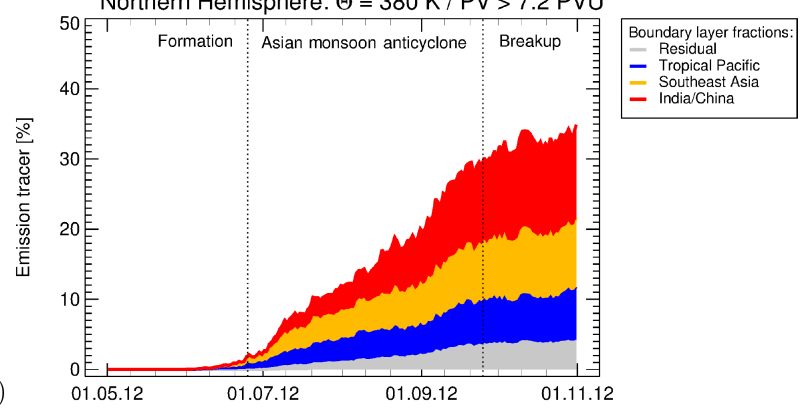

(b)

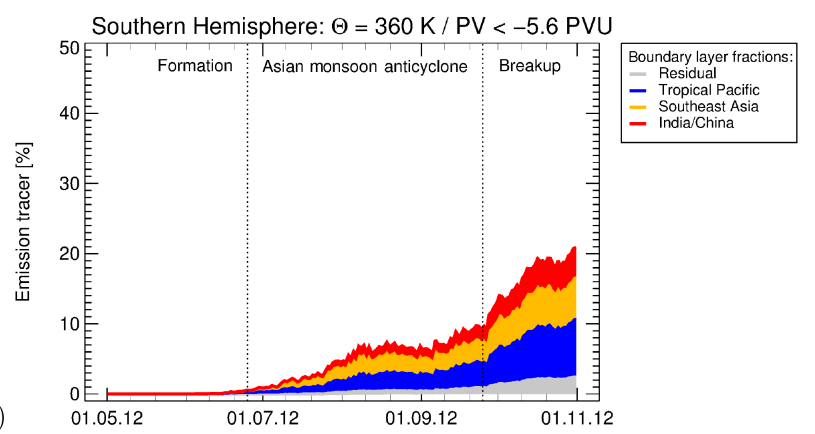

Figure 14. Contribution of different emission tracers from India/China, southeast Asia, the tropical Pacific Ocean, and residual surface to the northern lower stratosphere at different levels of potential temperature $360 \mathrm{~K}$ (a) and $380 \mathrm{~K}$ (b) from May to October 2012. The same for the southern lower stratosphere at $360 \mathrm{~K}$ (c).

maining fraction consisting of aged air. The highest contributions of the boundary emission tracers are from India/China (uplifted within the Asian monsoon anticyclone) from southeast Asia, and from the tropical Pacific Ocean. The contribution of all other regions of the Earth's surface (residual surface) are of minor importance (Table 2).

An equivalent analysis for the Southern Hemisphere (see Fig. 14c and Table 2) shows that the contribution of young air masses to the composition of southern extratropical lower stratosphere is much lower. At the end of October 2012, the contributions of all boundary emission tracers to the composition of the extratropical Southern Hemisphere lower stratosphere are at $340 \mathrm{~K} \approx 27 \%$, at $360 \mathrm{~K} \approx 21 \%$, and at $380 \mathrm{~K} \approx 2 \%$. Here, the highest contributions are from the tropical Pacific, southeast Asia, and only minor fractions are from India/China representing air masses from the Asian 
Table 2. The contributions of all boundary emission tracers to the composition of the extratropical lower stratosphere at the end of October 2012 at different levels of potential temperature using the climatological isentropic transport barrier derived by Kunz et al. (2015) for the Northern and Southern hemispheres. The highest contributions are from India/China, southeast Asia, and the tropical Pacific Ocean. The contributions of all other regions of the Earth's surface are of minor importance (residual surface).

\begin{tabular}{|c|c|c|c|}
\hline \multirow[t]{2}{*}{$\Theta$} & \multirow[t]{2}{*}{ Transport barrier } & \multicolumn{2}{|c|}{ Contribution of } \\
\hline & & $\begin{array}{r}\text { all boundary } \\
\text { tracers }\end{array}$ & $\begin{array}{r}\text { residual } \\
\text { surface }\end{array}$ \\
\hline \multicolumn{4}{|c|}{ Northern Hemisphere } \\
\hline $340 \mathrm{~K}$ & 3.8 PVU & $48 \%$ & $7 \%$ \\
\hline $360 \mathrm{~K}$ & 5.5 PVU & $44 \%$ & $5 \%$ \\
\hline $380 \mathrm{~K}$ & 7.2 PVU & $35 \%$ & $4 \%$ \\
\hline $400 \mathrm{~K}$ & $10.0 \mathrm{PVU}$ & $23 \%$ & $3 \%$ \\
\hline $420 \mathrm{~K}$ & $13.5 \mathrm{PVU}$ & $14 \%$ & $1 \%$ \\
\hline \multicolumn{4}{|c|}{ Southern Hemisphere } \\
\hline $340 \mathrm{~K}$ & $-3.0 \mathrm{PVU}$ & $27 \%$ & $3 \%$ \\
\hline $360 \mathrm{~K}$ & $-5.6 \mathrm{PVU}$ & $21 \%$ & $2 \%$ \\
\hline $380 \mathrm{~K}$ & $-11.5 \mathrm{PVU}$ & $2 \%$ & $<1 \%$ \\
\hline
\end{tabular}

monsoon anticyclone. Also here, the contribution of all other regions of the Earth's surface (residual surface) are of minor importance (see Table 2).

Our findings demonstrate the importance of the large-scale Asian monsoon system for the transport of young air masses from Asia and the tropical Pacific into the lower stratosphere of the Northern Hemisphere. This is particularly important for chemical species with lifetimes longer than a few months in the stratosphere, such as CO. In agreement with our simulations, during TACTS/ESMVal, an increase of the concentrations of long-lived tropospheric source gases (lifetimes $>3$ months) such as $\mathrm{CO}, \mathrm{H}_{2} \mathrm{O}$, and $\mathrm{N}_{2} \mathrm{O}$ was found by in situ aircraft measurements in the lower stratosphere over Europe from August to September associated with transport from the Asian monsoon anticyclone (Müller et al., 2016). These transport processes resulted in an accumulation of young air masses originating in boundary regions from Asia and the tropical Pacific Ocean within the lower stratosphere in the Northern Hemisphere during autumn 2012.

Because water vapor is an important greenhouse gas and even small perturbations of the water vapor mixing ratios in the ExUTLS have a significant impact on surface climate, we are interested in estimating the impact of the Asian monsoon on moistening the lower stratosphere. From our simulations, we roughly estimate the fraction of $\mathrm{H}_{2} \mathrm{O}$ originating in India/China, southeast Asia, and the tropical Pacific Ocean contributing to the water budget in the lower Northern Hemisphere stratosphere. Figure 15 shows the mean water vapor content in the northern lower stratosphere for PV val-
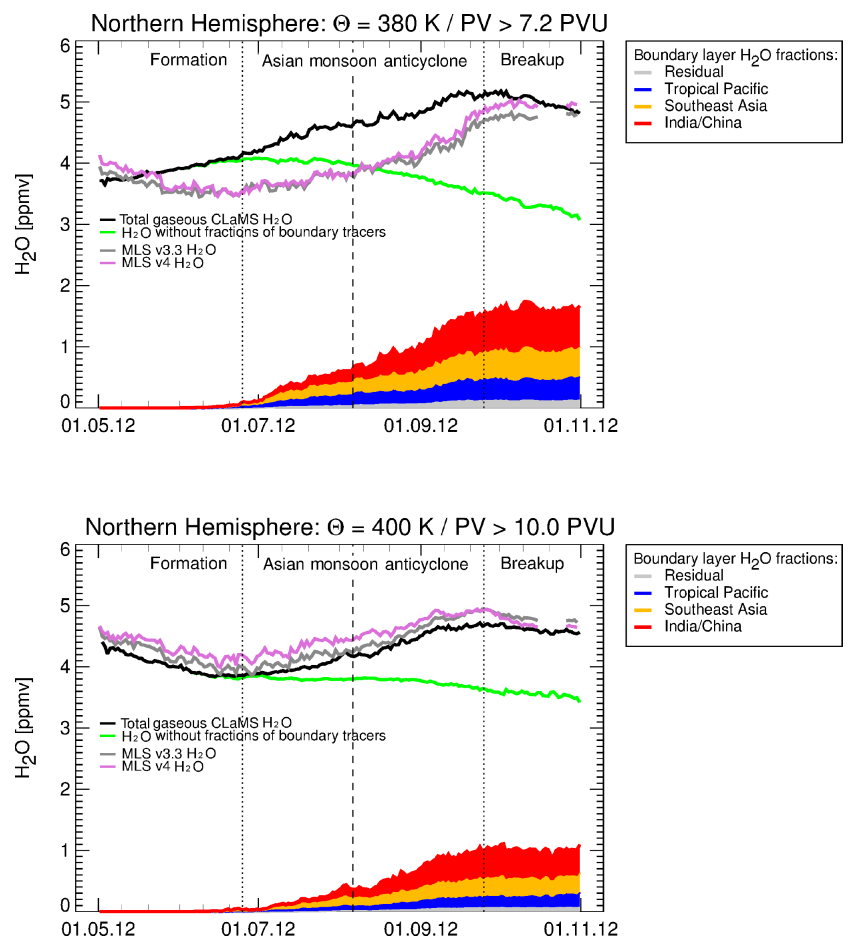

Figure 15. The increase of $\mathrm{H}_{2} \mathrm{O}$ mixing ratios in the lower Northern Hemisphere stratosphere at $380 \mathrm{~K}$ (top) and at $400 \mathrm{~K}$ (bottom) during summer 2012 is shown (black line). The green line indicates $\mathrm{H}_{2} \mathrm{O}$ mixing ratios without fractions from the Earth's boundary layer. Mean $\mathrm{H}_{2} \mathrm{O}$ mixing ratios derived from MLS version v3.3 (gray) and version $\mathrm{v} 4$ (purple) in the northern extratropical lower stratosphere also show an increase in water vapor during summer and autumn. A rough estimation of the fraction of $\mathrm{H}_{2} \mathrm{O}$ mixing ratios originating in India/China (red), southeast Asia (yellow), and the tropical Pacific Ocean (blue) in the northern lower stratosphere is also given.

ues larger than 7.2 PVU (10 PVU) and northward of $30^{\circ} \mathrm{N}$ at $380 \mathrm{~K}(400 \mathrm{~K})$ calculated with CLaMS (black line). In CLaMS at this altitude, contributions of cirrus clouds to the total water content are of minor importance. An increase of $\mathrm{H}_{2} \mathrm{O}$ in the northern lower stratosphere is found in our simulation during summer and autumn as reported in previous studies (e.g., Ploeger et al., 2013; Zahn et al., 2014; Müller et al., 2016). The fraction of $\mathrm{H}_{2} \mathrm{O}$ from different boundary tracers is indicated by different colors. At the end of October 2012, a contribution of approximately $1.5 \mathrm{ppmv}$ (1.0 ppmv) $\mathrm{H}_{2} \mathrm{O}$ originates from source regions in Asia and the tropical Pacific compared to a mean water vapor content of $\approx 5 \mathrm{ppm}$ $(4.5 \mathrm{ppm})$ at $380 \mathrm{~K}(400 \mathrm{~K})$. The total $\mathrm{H}_{2} \mathrm{O}$ without contributions from all boundary tracers, i.e., the contribution of aged air (see Fig. 15, green line) shows a decrease during summer and autumn. Mean $\mathrm{H}_{2} \mathrm{O}$ from AURA-MLS (version 3.3 and version 4) in the northern stratosphere calculated in a similar manner to the mean CLaMS $\mathrm{H}_{2} \mathrm{O}$ values for $\mathrm{PV}$ values larger than 7.2 PVU (10 PVU), and northward of $30^{\circ} \mathrm{N}$ at $380 \mathrm{~K}$ 
$(400 \mathrm{~K})$ also shows an increase of water vapor within the lower northern stratosphere during summer and autumn 2012 (see Fig. 15, gray and purple line) and therefore supports our findings from CLaMS simulations. Differences between CLaMS and MLS mean values in the lower northern stratosphere in particular at $380 \mathrm{~K}$ could be explained by sampling issues (different spatial resolution of MLS and CLaMS), vertical resolution of MLS limiting measurements of steep tracer gradient around the tropopause and the initialization of CLaMS $\mathrm{H}_{2} \mathrm{O}$ on 1 May 2012 (above $400 \mathrm{~K}$ : AURA-MLS; below $350 \mathrm{~K}$ : CLaMS multiannual simulation based on ERAInterim water vapor with a linear transition between 350 and $400 \mathrm{~K}$; for more details, see Vogel et al., 2015). Previous comparisons between CLaMS and MLS (v3.3) water vapor demonstrate that differences in $\mathrm{H}_{2} \mathrm{O}$ found in the lower stratosphere at high latitudes are likely an artifact of the MLS averaging kernels (Ploeger et al., 2013). Further, a comparison of water vapor climatologies from 11 different international limb sounders by Hegglin et al. (2013) demonstrate that AURA-MLS (v3.3) $\mathrm{H}_{2} \mathrm{O}$ measurements tend to be low at high latitudes in the lowermost stratosphere. Because of the good agreement between CLaMS $\mathrm{H}_{2} \mathrm{O}$ and in situ water vapor measurements by the FISH instrument during TACTS/ESMVal in the lower northern stratosphere (see Figs. 9-11) we are confident that CLaMS water vapor simulations within the extratropical lower stratosphere are reliable.

Thus, the increase of water vapor in the lower northern stratosphere during summer and autumn can be explained by the transport of young tropospheric air masses from Asia and the Pacific Ocean affected by the Asian monsoon anticyclone. We refer to this process as "flooding" of the lower stratosphere with young tropospheric air masses (although a contribution of aged stratospheric air remains). In previous papers (e.g., Hegglin and Shepherd, 2007; Müller et al., 2016) the expression "flushing" was also used. By using the word "flooding" we emphasize that the northern lower stratosphere is flooded with wet tropospheric young air masses from Asia and the tropical Pacific.

\section{Discussion and conclusions}

In this paper, the transport mechanisms are analyzed for air masses from inside the Asian monsoon anticyclone to the Northern Hemisphere lower stratosphere. The combination of the separation of anticyclones or filaments at the northeastern flank of the Asian monsoon anticyclone and subsequent horizontal transport along the subtropical jet associated with Rossby wave breaking is put forward here as a longrange transport mechanism from the Asian monsoon anticyclone to the Northern Hemisphere lower stratosphere. Our model simulations show that air masses originating in southeast Asia and in the tropical Pacific Ocean uplifted outside of the core of the Asian monsoon anticyclone also contribute to air masses of a tropospheric character found in the northern lower stratosphere. This is consistent with 40-day backward trajectory calculations for the TACTS flight on 26 September 2012 (region no. 2 in Fig. 9) showing that about 39\% of the trajectories originate in southeast Asia, the western Pacific, and the Asian monsoon region (Vogel et al., 2014). The residual $61 \%$ of the trajectories are from the background lower stratosphere. However, in the 3-D CLaMS simulations used here, irreversible mixing processes are additionally considered and a time period of 5 months (from 1 May 2012 to September 2012) is simulated, which is longer than the 40day backward trajectory calculations.

Our model simulation is driven by ERA-Interim reanalysis data. Convection in CLaMS is represented by vertical velocities in ERA-Interim reanalysis data. Thus, small-scale rapid uplift in convective cores is not included in CLaMS simulations. However, previous studies using 3-D CLaMS simulations or trajectory calculations (e.g., Ploeger et al., 2010, 2015; Pommrich et al., 2014; Vogel et al., 2014, 2015; Müller et al., 2016; Ungermann et al., 2016; Konopka et al., 2016), in comparison with satellite or in situ measurements, show that ERA-Interim data are well suited for studying transport processes in the vicinity of the Asian monsoon anticyclone and in the tropical tropopause layer.

Our findings show that the most important mechanism for long-range transport of air masses from the Asian monsoon anticyclone to the extratropical lower stratosphere is eastward-migrating anticyclones breaking off from the main anticyclone a few times each summer (Dethof et al., 1999; Popovic and Plumb, 2001; Garny and Randel, 2013; Vogel et al., 2014; Ploeger et al., 2015) and filaments separated on the northeastern flank of the anticyclone. In our case study for the eddy-shedding event on 20 September 2012, enhanced contributions of young air masses (younger than 5 months) are found within the separated anticyclone and filaments within the upper troposphere. Within the separated anticyclone, air masses with enhanced tropospheric tracers such as CO and enhanced values of artificial tracers of air mass origin are confined at the top by the thermal tropopause. On the polar side, the subtropical jet acts as a horizontal transport barrier. Therefore, the spatial structure of young air masses characterized by enhanced values of emission tracers from India/China resembles a bubble within the upper troposphere. These air masses are transported eastwards along the subtropical jet and most likely enter the extratropical lower stratosphere driven by Rossby wave breaking events associated with double tropopauses (e.g., Vaughan and Timmis, 1998; Castanheira and Gimeno, 2011; Ungermann et al., 2013; Homeyer and Bowman, 2013; Homeyer et al., 2014). Our simulations show that after entering the lower stratosphere, these air masses are mixed irreversibly with the surrounding stratospheric air. During the TACTS/ESMVal campaign in August and September 2012 conducted with the German Research Aircraft HALO, filaments with enhanced amounts of tropospheric trace gases such as $\mathrm{CO}, \mathrm{CH}_{4}$, and 


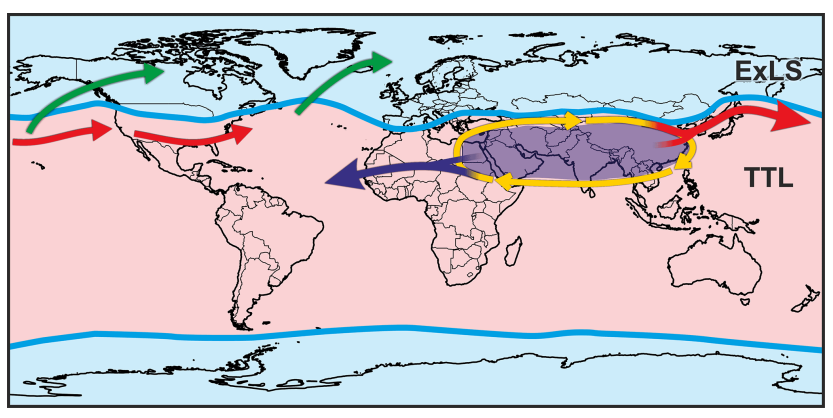

Figure 16. Horizontal transport pathways from the Asian monsoon anticyclone and the surrounding air masses (yellow) westward into the tropical tropopause layer (blue arrow) and eastward along the subtropical jet (red arrows). Cross-tropopause transport into the extratropical lower stratosphere occurs mainly above the Atlantic and Pacific oceans and is most likely driven by Rossby wave breaking events (green arrows).

$\mathrm{H}_{2} \mathrm{O}$, and reduced amounts of the stratospheric trace gas $\mathrm{O}_{3}$ compared to the stratospheric background were measured during three flights on 23, 25, and 26 September 2012 over northern Europe within the extratropical lower stratosphere. Our simulations confirm that these signatures are remnants of an eastward-migrating anticyclone and filaments released at the northeast flank of the Asian monsoon anticyclone that are transported to northern Europe within $\approx 8-14$ days.

In addition to this main transport pathway from the Asian monsoon anticyclone to the east along the subtropical jet and subsequent transport into the northern lower stratosphere, a second horizontal transport pathway out of the anticyclone to the west into the tropics (TTL) is found in agreement with MIPAS HCFC-22 measurements. This second transport pathway is mainly caused by westward eddy shedding. However, this transport pathway predominantly enhances the contribution of fresh emissions from India/China to the composition of TTL air at $380 \mathrm{~K}$ in summer and autumn 2012 (see Fig. 16).

Moreover, our simulation shows that young air masses originating in southeast Asia and the tropical Pacific Ocean also contribute substantially to the composition of the lower stratosphere over northern Europe in summer and autumn
2012. These air masses are globally distributed during summer and autumn on the tropical side of the subtropical jet stream of the Northern Hemisphere (see Appendix A). A large-scale movement of these air masses around the Asian monsoon anticyclone is found in our model simulations, indicating that the Asian monsoon anticyclone acts as a large stirrer within the TTL, causing mixing of young air masses from southeast Asia and the tropical Pacific Ocean into the TTL. Subsequent transport into the northern lower stratosphere most likely by Rossby wave breaking events results in an increase of young air masses within the lower northern stratosphere.

Our findings demonstrate that young air masses originating in India/China and southeast Asia, and the tropical Pacific Ocean affected by the circulation of the Asian monsoon anticyclone have a significant impact on the chemical compositions of the lower stratosphere of the Northern Hemisphere. Young, moist air masses flooded the extratropical lower stratosphere in the Northern Hemisphere with contributions of up to $\approx 30 \%$ at $380 \mathrm{~K}$ (with the remaining fraction being aged air) at the end of the monsoon season in September/October 2012. In contrast, the contribution of young air masses to the Southern Hemisphere is much lower. Our model simulations show that transport from boundary sources in Asia and the tropical Pacific during summer and autumn resulted in moistening of the lower northern stratosphere (by roughly $\approx 1.5 / 1.0 \mathrm{ppmv}$ at $380 / 400 \mathrm{~K}$ end of October 2012) which could have an impact on surface climate.

\section{Data availability}

The complete MIPAS data are available at http://www. imk-asf.kit.edu/english/308.php and AURA-MLS water vapor is available at http://www.annalsofgeophysics.eu/index. php/annals/article/view/6339. The data of TACTS/ESMVal aircraft measurements are included in the HALO database available at https://halo-db.pa.op.dlr.de/list/missions. 


\section{Appendix A: Additional emission tracers}

\section{Horizontal distributions of emission tracers for southeast Asia and the tropical Pacific Ocean}

Figures 10 and 11 show that air masses originating in southeast Asia and in the tropical Pacific also contribute to the composition of the lower stratosphere over northern Europe. The horizontal distribution of the emission tracers of southeast Asia and the tropical Pacific at $380 \mathrm{~K}$ from July to September 2012 are shown in Fig. A1. Air masses with enhanced percentages of the emission tracer for the tropical Pacific Ocean are found over the Maritime Continent and the western Pacific in July and August 2012, indicating upward transport outside of the Asian monsoon anticyclone (see Fig. 12a and b). In September 2012, enhanced values are also found westward and eastward of the maritime continent, indicating horizontal transport within the TTL (see Fig. A1c and d, left). Low values are found in the regions of the Asian monsoon anticyclone, indicating the transport barrier around the anticyclone which inhibits a horizontal exchange of air masses. Further transport into the northern lower stratosphere also occurs most likely by Rossby wave breaking events along the subtropical jet similar to that for air masses from the Asian monsoon anticyclone (enhanced contributions from India/China; see Fig. 12).
Air masses with enhanced contributions from southeast Asia are found both within the Asian monsoon anticyclone and over the maritime continent and the western Pacific caused by the geographical position of the emission tracer of southeast Asia, as shown in Fig. A1 (right). Thus, enhanced contributions from southeast Asia are found as a superposition of transport within the Asian monsoon anticyclone and outside in the western Pacific region as is evident in the horizontal distribution of the emission tracer for southeast Asia. 
(a)
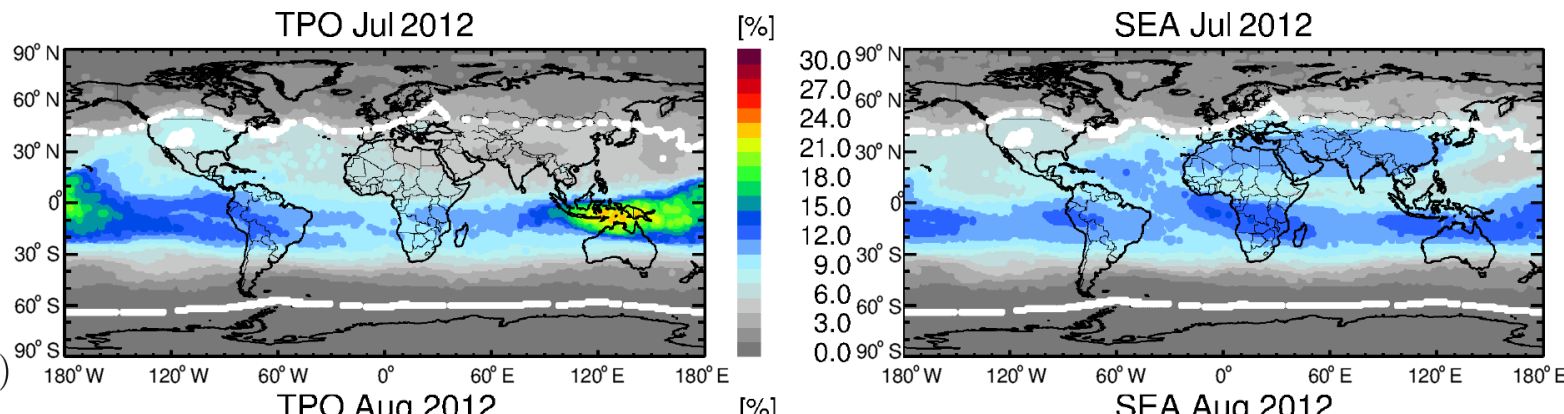

[\%]

30.0

27.0

24.0

21.0

18.0

15.0

12.0

9.0

6.0

3.0

[\%]

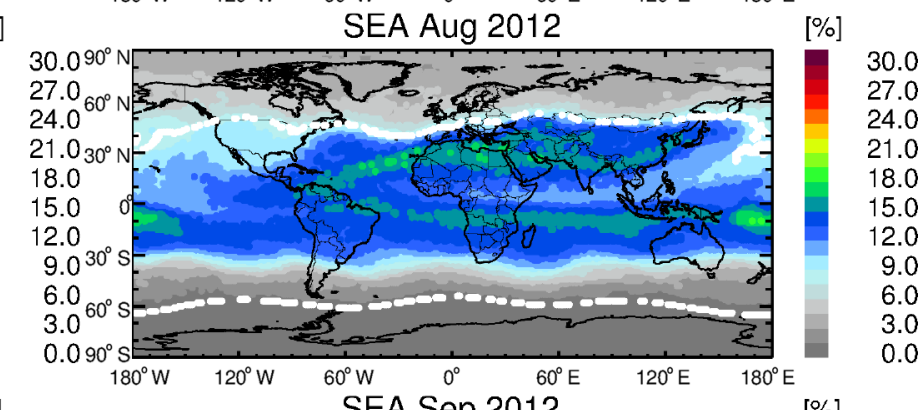

(b)

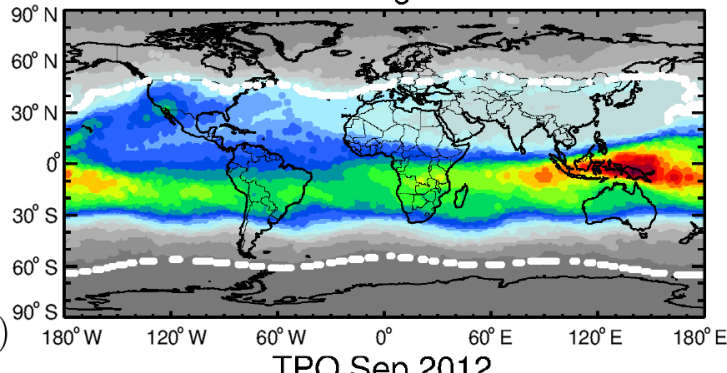

[\%]
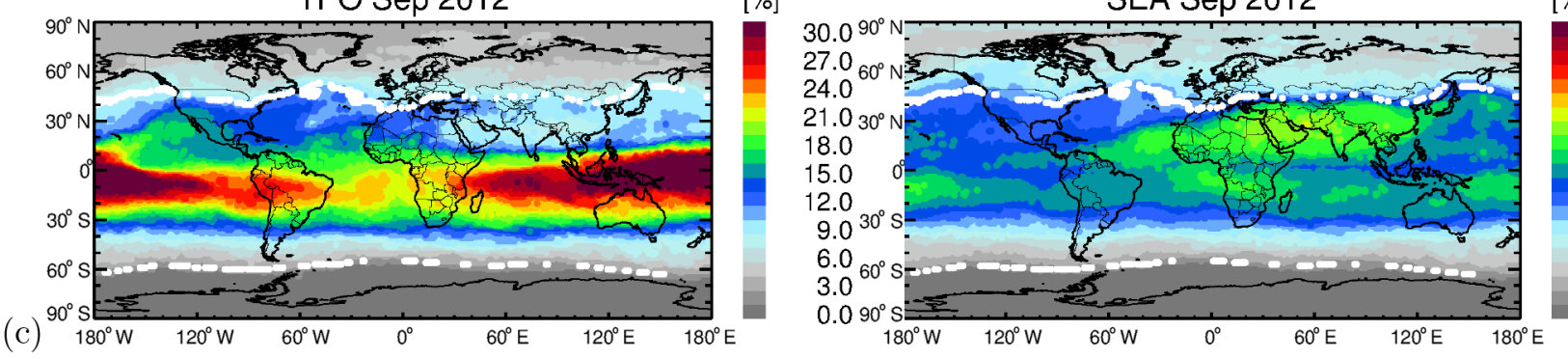

[\%]

30.0

27.0

24.0

21.0

8.0

15.0

12.0

6.0

3.0

0.0

Figure A1. Mean values of the contribution of the emission tracer for the tropical Pacific Ocean (left) and southeast Asia (right) at $380 \mathrm{~K}$ in July (a), August (b), and September (c) 2012. The climatological isentropic transport barriers of 7.2 PVU (Northern Hemisphere) and $-11.5 \mathrm{PVU}$ (Southern Hemisphere) at $380 \mathrm{~K}$ are shown as thick white dots. 


\section{Appendix B: Description of interpolation method}

\section{Full 3-D Delaunay triangulation}

In this study, the interpolation method used to determine the mixing ratios of chemical species and percentages of artificial tracers of air mass origin along the path of the TACTS/ESMVal flights (see Figs. 9-11) from CLaMS data is upgraded from the previously used semi-2-D scheme to a full 3-D Delaunay triangulation.

As a first step, CLaMS backward trajectories are calculated from the time and space of the measurements for the CLaMS model output at noon 1 day before the measurement. Subsequently, the CLaMS data calculated on an irregular grid are interpolated on the endpoints of the backward trajectories as described below.

The complexity of creating the Delaunay triangulation increases in the worst case with the square of the inserted points. To reduce the number of points and to eliminate the spherical shape of the points, it is advantageous to partition the surface of the Earth into six latitudinal bands $\left(0-36^{\circ}, 36-\right.$ $72^{\circ}$, and $72-90^{\circ}$ for each hemisphere). The four latitudinal bands between $72^{\circ} \mathrm{S}$ and $72^{\circ} \mathrm{N}$ are additionally split into longitudinal areas (every $36^{\circ}$ for the two bands between 0 and $36^{\circ}$; every $45^{\circ}$ for the two bands between 36 and $72^{\circ}$ ). This partitioning was selected to give areas of roughly equal size with a sufficient number of air parcels. Within each of these areas, a Cartesian 3-D Delaunay triangulation including all contained parcels and a certain amount of neighboring parcels (here extending each area by $25 \%$ in longitude and latitude) is employed (Delaunay, 1934). The chosen amount of overlap assures that all relevant parcels surrounding the area are included in the triangulation for the typical air parcel density of the examined simulations. The coordinate system employed for each area is locally projected using a stereographic projection on the horizontal center of each area.

In the CLaMS simulation used here, a horizontal resolution of $100 \mathrm{~km}$ is employed with a maximum vertical resolution (thickness of the model layer) of about $400 \mathrm{~m}$ around the tropopause and thicker layers above and below the tropopause (in general, the geometrical thickness of a layer $\Delta z$ is described by $\Delta z=\alpha \Delta r$ with the aspect ratio $\alpha$ and the horizontal resolution $\Delta r ; \alpha$ is controlled by the assumption that the entropy of the system is uniformly distributed over all air parcels; for more details, see Konopka et al., 2012; Pommrich et al., 2014). The previously used semi-2-D scheme interpolation is effectively restricted to occur within one model layer.
The thickness of each layer in hybrid coordinates is defined corresponding to a fixed amount of a virtual altitude in kilometer $\delta$ within the coordinate system of each area. The vertical position of each air parcel within a layer is assigned to the virtual coordinate by its relative position in the layer: if the boundaries of the layers are defined as $\zeta_{i}$ with $\zeta_{i+1}>\zeta_{i}$, $i \in \mathbb{N}_{0}$, then the virtual vertical coordinate $z^{\prime}$ of an air parcel with a vertical hybrid coordinate $\zeta$ within one area is defined as

$z^{\prime}=\left(i+\frac{\zeta-\zeta_{i}}{\zeta_{i+1}-\zeta_{i}}\right) \cdot \delta$.

For the CLaMS simulation used here, a factor of $100 \mathrm{~km}$ was chosen for $\delta$, corresponding to the typical horizontal distance of parcels within one layer according to the horizontal resolution.

Not used here, but useful for other applications is a simple linear relationship between the potential temperature of an air parcel and its virtual vertical altitude of, e.g., $z^{\prime}=$ $\theta \cdot 10 \mathrm{~km} \mathrm{~K}^{-1}$.

Using the coordinate transformation with the virtual vertical coordinate as defined in Eq. (B1) and using the segmentation in different latitude-longitude areas, the triangulation can be calculated in Cartesian coordinates involving a strongly reduced number of air parcels compared to all the air parcels of the model simulation. Using the 3-D triangulation, several fast and useful interpolation options are readily available, such as nearest neighbor or barycentric interpolation. We choose to employ natural neighbor (or Sibson) interpolation (Sibson, 1981), which computes the weighted means of all neighboring points in contrast to methods such as barycentric interpolation, which use only neighboring points spanning a tetrahedron around the enclosed air parcel.

The Computational Geometry Algorithms Library (CGAL) offers all the routines necessary to efficiently implement the algorithm described (Pion and Teillaud, 2013). The algorithm and its variants were implemented as a Python module known as juregrid3d (Jülich Regridding 3-D) using $\mathrm{C}++$ and Cython for the performance critical parts. 
Acknowledgements. We would like to sincerely thank Andreas Engel and Harald Bönisch (University of Frankfurt) for coordinating the TACTS campaign, Hans Schlager (DLR Oberpfaffenhofen) for coordinating the ESMVal campaign, the HALO crew, and the HALO pilots. The authors gratefully acknowledge Laura Pan (NCAR, Boulder) and Eric Jensen (NASA Ames Research Center, Moffett Field) for helpful discussions on transport pathways in the Asian monsoon circulation and their impact on moistening the lower stratosphere. In particular, we thank Laura Pan for comments on the concept of the Asian Monsoon anticyclone as a "tropospheric bubble". We would like to sincerely thank Paul Konopka (Research Centre Jülich) for providing lower boundary conditions for $\mathrm{CO}$ and $\mathrm{CH}_{4}$ derived from AIRS (atmospheric infrared sounder) satellite measurements used in CLaMS multiannual simulations. We thank the MLS scientific team (AURA Microwave Limb Sounder) for providing satellite data and the European Centre for Medium-Range Weather Forecasts (ECMWF) for providing the ERA-Interim reanalysis data. The authors gratefully acknowledge the computing time granted on the supercomputer JUROPA at Jülich Supercomputing Centre (JSC) as part of the VSR project ID JICG11. Our activities were partly funded by the German Science Foundation (Deutsche Forschungsgemeinschaft) as part of the LASSO project (HALO-SPP 1294/GR 3786) and by the European Community's Seventh Framework Programme (FP7/2007-2013) as part of the StratoClim project (grant agreement no. 603557). The authors would also like to thank three anonymous reviewers for their very helpful comments.

The article processing charges for this open-access publication were covered by a Research

Centre of the Helmholtz Association.

Edited by: P. Haynes

Reviewed by: three anonymous referees

\section{References}

Anderson, J., Wilmouth, D., Smith, J., and Sayres, D.: UV Dosage Levels in Summer: Increased Risk of Ozone Loss from Convectively Injected Water Vapor, Science, 337, 835-839, doi:10.1126/science.1222978, 2012.

Bian, J., Pan, L. L., Paulik, L., Vömel, H., and Chen, H.: In situ water vapor and ozone measurements in Lhasa and Kunmin during the Asian summer monsoon, Geophys. Res. Lett., 39, L19808, doi:10.1029/2012GL052996, 2012.

Bönisch, H., Engel, A., Curtius, J., Birner, Th., and Hoor, P.: Quantifying transport into the lowermost stratosphere using simultaneous in-situ measurements of $\mathrm{SF}_{6}$ and $\mathrm{CO}_{2}$, Atmos. Chem. Phys., 9, 5905-5919, doi:10.5194/acp-9-5905-2009, 2009.

Bourassa, A. E., Robock, A., Randel, W. J., Deshler, T., Rieger, L. A., Lloyd, N. D., Llewellyn, E. J. T., and Degenstein, D. A.: Large Volcanic Aerosol Load in the Stratosphere Linked to Asian Monsoon Transport, Science, 337, 78-81, doi:10.1126/science.1219371, 2012.

Brasseur, G. and Solomon, S.: Aeronomy of the Middle Atmosphere: Chemistry and Physics of the Stratosphere and Mesosphere, Springer, Heidelberg, Germany, 3rd Edn., 2005.
Castanheira, J. M. and Gimeno, L.: Association of double tropopause events with baroclinic waves, J. Geophys. Res., 116, D19113, doi:10.1029/2011JD016163, 2011.

Chirkov, M., Stiller, G. P., Laeng, A., Kellmann, S., von Clarmann, T., Boone, C. D., Elkins, J. W., Engel, A., Glatthor, N., Grabowski, U., Harth, C. M., Kiefer, M., Kolonjari, F., Krummel, P. B., Linden, A., Lunder, C. R., Miller, B. R., Montzka, S. A., Mühle, J., O’Doherty, S., Orphal, J., Prinn, R. G., Toon, G., Vollmer, M. K., Walker, K. A., Weiss, R. F., Wiegele, A., and Young, D.: Global HCFC-22 measurements with MIPAS: retrieval, validation, global distribution and its evolution over 2005-2012, Atmos. Chem. Phys., 16, 3345-3368, doi:10.5194/acp-16-3345-2016, 2016.

Dee, D. P., Uppala, S. M., Simmons, A. J., Berrisford, P., Poli, P., Kobayashi, S., Andrae, U., Balmaseda, M. A., Balsamo, G., Bauer, P., Bechtold, P., Beljaars, A. C. M., van de Berg, L., Bidlot, J., Bormann, N., Delsol, C., Dragani, R., Fuentes, M., Geer, A. J., Haimberger, L., Healy, S. B., Hersbach, H., Holm, E. V., Isaksen, L., Kallberg, P., Koehler, M., Matricardi, M., McNally, A. P., Monge-Sanz, B. M., Morcrette, J.-J., Park, B.-K., Peubey, C., de Rosnay, P., Tavolato, C., Thepaut, J.-N., and Vitart, F.: The ERA-Interim reanalysis: configuration and performance of the data assimilation system, Q. J. Roy. Meteor. Soc., 137, 553-597, doi:10.1002/qj.828, 2011.

Delaunay, B.: Sur la sphère vide, A la mémoire de Georges Voronoï, B. Acad. Sci. URSS, 6, 793-800, 1934.

Dethof, A., O’Neill, A., Slingo, J. M., and Smit, H. G. J.: A mechanism for moistening the lower stratosphere involving the Asian summer monsoon, Q. J. Roy. Meteor. Soc., 556, 1079-1106, 1999.

Dvortsov, V. L. and Solomon, S.: Response of the stratospheric temperatures and ozone to past and future increases in stratospheric humidity, J. Geophys. Res., 106, 7505-7514, 2001.

Fairlie, T. D., Avery, M. A., Pierce, R. B., Al-Saadi, J., Dibb, J., and Sachse, G.: Impact of multiscale dynamical processes and mixing on the chemical composition of the upper troposphere and lower stratosphere during the Intercontinental Chemical Transport Experiment-North America, J. Geophys. Res., 112, D16S90, doi:10.1029/2006JD007923, 2007.

Fairlie, T. D., Vernier, J.-P., Natarajan, M., and Bedka, K. M.: Dispersion of the Nabro volcanic plume and its relation to the Asian summer monsoon, Atmos. Chem. Phys., 14, 7045-7057, doi:10.5194/acp-14-7045-2014, 2014.

Fortems-Cheiney, A., Chevallier, F., Saunois, M., Pison, I., Bousquet, Cressot, C., Wang, H. J., Yokouchi, Y., and Artuso, F.: HCFC-22 emissions at global and regional scales between 1995 and 2010: Trends and variability, J. Geophys. Res., 118, 73797388, doi:10.1002/jgrd.50544, 2013.

Fromm, M., Kablick III, G., Nedoluha, G., Carboni, E., Grainger, R., Campbell, J., and Lewis, J.: Correcting the record of volcanic stratospheric aerosol impact: Nabro and Sarychev Peak, J. Geophys. Res., 119, 10343-10364, doi:10.1002/2014JD021507, 2014.

Garny, H. and Randel, W. J.: Dynamic variability of the Asian monsoon anticyclone observed in potential vorticity and correlations with tracer distributions, J. Geophys. Res., 118, 13421-13433, doi:10.1002/2013JD020908, 2013. 
Garny, H. and Randel, W. J.: Transport pathways from the Asian monsoon anticyclone to the stratosphere, Atmos. Chem. Phys., 16, 2703-2718, doi:10.5194/acp-16-2703-2016, 2016.

Grooß, J.-U., Engel, I., Borrmann, S., Frey, W., Günther, G., Hoyle, C. R., Kivi, R., Luo, B. P., Molleker, S., Peter, T., Pitts, M. C., Schlager, H., Stiller, G., Vömel, H., Walker, K. A., and Müller, R.: Nitric acid trihydrate nucleation and denitrification in the Arctic stratosphere, Atmos. Chem. Phys., 14, 1055-1073, doi:10.5194/acp-14-1055-2014, 2014.

Günther, G., Müller, R., von Hobe, M., Stroh, F., Konopka, P., and Volk, C. M.: Quantification of transport across the boundary of the lower stratospheric vortex during Arctic winter 2002/2003, Atmos. Chem. Phys., 8, 3655-3670, doi:10.5194/acp-8-36552008, 2008.

Hegglin, M. I. and Shepherd, T. G.: $\mathrm{O}_{3}-\mathrm{N}_{2} \mathrm{O}$ correlations from the Atmospheric Chemistry Experiment: Revisiting a diagnostic of transport and chemistry in the stratosphere, J. Geophys. Res., D19301, doi:10.1029/2006JD008281, 2007.

Hegglin, M. I., Tegtmeier, S., Anderson, J., Froidevaux, L., Fuller, R., Funke, B., Jones, A., Lingenfelser, G., Lumpe, J., Pendlebury, D., Remsberg, E., Rozanov, A., Toohey, M., Urban, J., von Clarmann, T., Walker, K. A., Wang, R., and Weigel, K.: SPARC Data Initiative: Comparison of water vapor climatologies from international satellite limb sounders, J. Geophys. Res., 118, 1182411846, doi:10.1002/jgrd.50752, 2013.

Homeyer, C. R. and Bowman, K. P.: Rossby wave breaking and transport between the tropics and extratropics above the subtropical jet, J. Atmos. Sci., 70, 607-626, 2013.

Homeyer, C. R., Bowman, K. P., Pan, L. L., Atlas, E. L., Gao, R.S., and Campos, T. L.: Dynamical and chemical characteristics of tropospheric intrusions observed during START08, J. Geophys. Res., 116, D06111, doi:10.1029/2010JD015098, 2011.

Homeyer, C. R., Pan, L. L., Dorsi, S. W., Avallone, L. M., Weinheimer, A. J., O’Brien, A. S., DiGangi, J. P., Zondlo, M. A., Ryerson, T. B., Diskin, G. S., and Campos, T. L.: Convective transport of water vapor into the lower stratosphere observed during double-tropopause events, J. Geophys. Res., 119, 10941-10958, doi:10.1002/2014JD021485, 2014.

Hoor, P., Gurk, C., Brunner, D., Hegglin, M. I., Wernli, H., and Fischer, H.: Seasonality and extent of extratropical TST derived from in-situ CO measurements during SPURT, Atmos. Chem. Phys., 4, 1427-1442, doi:10.5194/acp-4-1427-2004, 2004.

Hoor, P., Fischer, H., and Lelieveld, J.: Tropical and extratropical tropospheric air in the lowermost stratosphere over Europe: A CO-based budget, Geophys. Res. Lett., 32, L07802, doi:10.1029/2004GL022018, 2005.

Hossaini, R., Chipperfield, M., Montzka, M. P., Rap, S. A., Dhomse, S., and Feng, W.: Efficiency of short-lived halogens at influencing climate through depletion of stratopsheric ozone, Nat. Geosci., 8, 186-190, doi:10.1038/ngeo2363, 2015.

Hsu, C. J. and Plumb, R. A.: Nonaxisymmetric Thermally Driven Circulations and Upper-Tropospheric Monsoon Dynamics, J. Atmos. Sci., 57, 1255-1276, 2001.

Kirk-Davidoff, D. B., Hintsa, E. J., Anderson, J. G., and Keith, D. W.: The effect of climate change on ozone depletion through changes in stratospheric water vapour, Nature, 402, 399-401, doi:10.1038/46521, 1999.
Konopka, P. and Pan, L. L.: On the mixing-driven formation of the Extratropical Transition Layer (ExTL), J. Geophys. Res., 117, D18301, doi:10.1029/2012JD017876, 2012.

Konopka, P., Grooß, J.-U., Günther, G., Ploeger, F., Pommrich, R., Müller, R., and Livesey, N.: Annual cycle of ozone at and above the tropical tropopause: observations versus simulations with the Chemical Lagrangian Model of the Stratosphere (CLaMS), Atmos. Chem. Phys., 10, 121-132, doi:10.5194/acp-10-121-2010, 2010.

Konopka, P., Ploeger, F., and Müller, R.: Entropy- and static stability-based Lagrangian model grids, in: Geophysical Monograph Series: Lagrangian Modeling of the Atmosphere, edited by: Lin, J., American Geophysical Union, Washington, DC, 200, 99-109, doi:10.1029/2012GM001253, 2012.

Konopka, P., Ploeger, F., Tao, M., and Riese, M.: Regionally resolved impact of ENSO on the variability of the BrewerDobson circulation and of water vapor entering the tropical lower stratosphere, J. Geophys. Res., 121, 11486-11501, doi:10.1002/2015JD024698, 2016.

Kunz, A., Sprenger, M., and Wernli, H.: Climatology of potential vorticity streamers and associated isentropic transport pathways across PV gradient barriers, J. Geophys. Res., 120, 3802-3821, doi:10.1002/2014JD022615, 2015.

Li, Q., Jiang, J. H., Wu, D. L., Read, W. G., Livesey, N. J., Waters, J. W., Zhang, Y., Wang, B., Filipiak, M. J., Davis, C. P., Turquety, S., Wu, S., Park, R. J., Yantosca, R. M., and Jacob, D. J.: Convective outflow of South Asian pollution: A global CTM simulation compared with EOS MLS observations, Geophys. Res. Lett., 32, L14826, doi:10.1029/2005GL022762, 2005.

Livesey, N. J., Read, W. G., Froidevaux, L., Lambert, A., Manney, G. L., Pumphrey, H. C., Santee, M. L., Schwartz, M. J., Wang, S., Cofield, R. E., Cuddy, D. T., Fuller, R. A., Jarnot, R. F., Jiang, J. H., Knosp, B. W., Stek, P. C., Wagner, P. A., , and Wu, D. L.: EOS MLS Version 3.3 Level 2 data quality and description document, Tech. Rep. JPL D33509, Jet Propulsion Laboratory, 2011.

McKenna, D. S., Grooß, J.-U., Günther, G., Konopka, P., Müller, R., Carver, G., and Sasano, Y.: A new Chemical Lagrangian Model of the Stratosphere (CLaMS): 2. Formulation of chemistry scheme and initialization, J. Geophys. Res., 107, 4256 , doi:10.1029/2000JD000113, 2002a.

McKenna, D. S., Konopka, P., Grooß, J.-U., Günther, G., Müller, R., Spang, R., Offermann, D., and Orsolini, Y.: A new Chemical Lagrangian Model of the Stratosphere (CLaMS): 1. Formulation of advection and mixing, J. Geophys. Res., 107, 4309, doi:10.1029/2000JD000114, 2002b.

Meyer, J., Rolf, C., Schiller, C., Rohs, S., Spelten, N., Afchine, A., Zöger, M., Sitnikov, N., Thornberry, T. D., Rollins, A. W., Bozóki, Z., Tátrai, D., Ebert, V., Kühnreich, B., Mackrodt, P., Möhler, O., Saathoff, H., Rosenlof, K. H., and Krämer, M.: Two decades of water vapor measurements with the FISH fluorescence hygrometer: a review, Atmos. Chem. Phys., 15, 85218538, doi:10.5194/acp-15-8521-2015, 2015.

Müller, S., Hoor, P., Bozem, H., Gute, E., Vogel, B., Zahn, A., Bönisch, H., Keber, T., Krämer, M., Rolf, C., Riese, M., Schlager, H., and Engel, A.: Impact of the Asian monsoon on the extratropical lower stratosphere: trace gas observations during TACTS over Europe 2012, Atmos. Chem. Phys., 16, 10573-10589, doi:10.5194/acp-16-10573-2016, 2016. 
Orbe, C., Waugh, D. W., and Newman, P. A.: Air-mass origin in the tropical lower stratosphere: The influence of Asian boundary layer air, Geophys. Res. Lett., 42, 4240-4248, doi:10.1002/2015GL063937, 2015.

Pan, L. L., Konopka, P., and Browell, E. V.: Observations and model simulations of mixing near the extratropical tropopause, J. Geophys. Res., 111, D05106, doi:10.1029/2005JD006480, 2006.

Pan, L. L., Randel, W. J., Gille, J. C., Hall, W. D., Nardi, B., Massie, S., Yudin, V., Khosravi, R., Konopka, P., and Tarasick, D.: Tropospheric intrusions associated with the secondary tropopause, J. Geophys. Res., 114, D10302, doi:10.1029/2008JD011374, 2009.

Pan, L. L., Honomichl, S. B., Kinnison, D. E., Abalos, M., Randel, W. J., Bergman, J. W., and Bian, J.: Transport of chemical tracers from the boundary layer to the stratosphere associated with the dynamics of the Asian summer monsoon, J. Geophys. Res.Atmos., doi:10.1002/2016JD025616, online first, 2016.

Park, M., Randel, W. J., Kinnison, D. E., Garcia, R. R., and Choi, W.: Seasonal variation of methane, water vapor, and nitrogen oxides near the tropopause: Satellite observations and model simulations, J. Geophys. Res., 109, D03302, doi:10.1029/2003JD003706, 2004.

Park, M., Randel, W. J., Gettleman, A., Massie, S. T., and Jiang, J. H.: Transport above the Asian summer monsoon anticyclone inferred from Aura Microwave Limb Sounder tracers, J. Geophys. Res., 112, D16309, doi:10.1029/2006JD008294, 2007.

Park, M., Randel, W. J., Emmons, L. K., Bernath, P. F., Walker, K. A., and Boone, C. D.: Chemical isolation in the Asian monsoon anticyclone observed in Atmospheric Chemistry Experiment (ACE-FTS) data, Atmos. Chem. Phys., 8, 757-764, doi:10.5194/acp-8-757-2008, 2008.

Park, M., Randel, W. J., Emmons, L. K., and Livesey, N. J.: Transport pathways of carbon monoxide in the Asian summer monsoon diagnosed from Model of Ozone and Related Tracers (MOZART), J. Geophys. Res., 114, D08303, doi:10.1029/2008JD010621, 2009.

Pion, S. and Teillaud, M.: 3D Triangulations, in: CGAL User and Reference Manual, CGAL Editorial Board, 4.2 Edn., available at: http://doc.cgal.org/4.2/CGAL.CGAL/html/ packages.html\#PkgTriangulation3Summary, 2013.

Ploeger, F., Konopka, P., Günther, G., Grooß, J.-U., and Müller, R.: Impact of the vertical velocity scheme on modeling transport across the tropical tropopause layer, J. Geophys. Res., 115, D03301, doi:10.1029/2009JD012023, 2010.

Ploeger, F., Günther, G., Konopka, P., Fueglistaler, S., Müller, R., Hoppe, C., Kunz, A., Spang, R., Grooß, J.-U., and Riese, M.: Horizontal water vapor transport in the lower stratosphere from subtropics to high latitudes during boreal summer, J. Geophys. Res., 118, 8111-8127, doi:10.1002/jgrd.50636, 2013.

Ploeger, F., Gottschling, C., Griessbach, S., Grooß, J.-U., Guenther, G., Konopka, P., Müller, R., Riese, M., Stroh, F., Tao, M., Ungermann, J., Vogel, B., and von Hobe, M.: A potential vorticitybased determination of the transport barrier in the Asian summer monsoon anticyclone, Atmos. Chem. Phys., 15, 13145-13159, doi:10.5194/acp-15-13145-2015, 2015.

Pommrich, R., Müller, R., Grooß, J.-U., Konopka, P., Ploeger, F., Vogel, B., Tao, M., Hoppe, C. M., Günther, G., Spelten, N., Hoffmann, L., Pumphrey, H.-C., Viciani, S., D’Amato, F., Volk, C. M., Hoor, P., Schlager, H., and Riese, M.: Tropical troposphere to stratosphere transport of carbon monoxide and long-lived trace species in the Chemical Lagrangian Model of the Stratosphere (CLaMS), Geosci. Model Dev., 7, 2895-2916, doi:10.5194/gmd7-2895-2014, 2014.

Popovic, J. M. and Plumb, R. A.: Eddy Shedding from the UpperTropospheric Asian Monsoon Anticyclone, J. Atmos. Sci., 58, 93-104, 2001.

Randel, W. J. and Park, M.: Deep convective influence on the Asian summer monsoon anticyclone and associated tracer variability observed with Atmospheric Infrared Sounder (AIRS), J. Geophys. Res., 111, D12314, doi:10.1029/2005JD006490, 2006.

Randel, W. J., Park, M., Emmons, L., Kinnison, D., Bernath, P., Walker, K. A., Boone, C., and Pumphrey, H.: Asian Monsoon Transport of Pollution to the Stratosphere, Science, 328, 611613, doi:10.1126/science.1182274, 2010.

Riese, M., Ploeger, F., Rap, A., Vogel, B., Konopka, P., Dameris, M., and Forster, P.: Impact of uncertainties in atmospheric mixing on simulated UTLS composition and related radiative effects, J. Geophys. Res., 117, D16305, doi:10.1029/2012JD017751, 2012.

Sander, S. P., Friedl, R. R., Barker, J. R., Golden, D. M., Kurylo, M. J., Wine, P. H., Abbatt, J. P. D., Burkholder, J. B., Kolb, C. E., Moortgat, G. K., Huie, R. E., and Orkin, V. L.: Chemical kinetics and photochemical data for use in atmospheric studies, JPL Publication 10-6, 2011.

Schwartz, M. J., Manney, G. L., Hegglin, M. I., Livesey, N. J., Santee, M. L., and Daffer, W. H.: Climatology and variability of trace gases in extratropical double-tropopause regions from MLS, HIRDLS and ACE-FTS measurements, J. Geophys. Res., 120, 843-867, doi:10.1002/2014JD021964, 2015.

Sibson, R.: A brief description of natural neighbor interpolation, in: Interpreting Multivariate Data, Chichester, edited by: Barnett, V., John Wiley, 21-36, 1981.

Solomon, S., Rosenlof, K., Portmann, R., Daniel, J., Davis, S., Sanford, T., and Plattner, G.-K.: Contributions of stratospheric water vapor to decadal changes in the rate of global warming, Science, 327, 1219-1223, doi:10.1126/science.1182488, 2010.

Spang, R., Günther, G., Riese, M., Hoffmann, L., Müller, R., and Griessbach, S.: Satellite observations of cirrus clouds in the Northern Hemisphere lowermost stratosphere, Atmos. Chem. Phys., 15, 927-950, doi:10.5194/acp-15-927-2015, 2015.

Sprenger, M., Wernli, H., and Bourqui, M.: StratosphereTroposphere Exchange and Its Relation to Potential Vorticity Streamers and Cutoffs near the Extratropical Tropopause, J. Atmos. Sci., 64, 1587-1602, doi:10.1175/JAS3911.1, 2007.

Tissier, A.-S. and Legras, B.: Convective sources of trajectories traversing the tropical tropopause layer, Atmos. Chem. Phys., 16, 3383-3398, doi:10.5194/acp-16-3383-2016, 2016.

Uma, K. N., Das, S. K., and Das, S. S.: A climatological perspective of water vapor at the UTLS region over different global monsoon regions: observations inferred from the Aura-MLS and reanalysis data, Clim. Dynam., 43, 407-420, doi:10.1007/s00382-0142085-9, 2014.

Ungermann, J., Pan, L. L., Kalicinsky, C., Olschewski, F., Knieling, P., Blank, J., Weigel, K., Guggenmoser, T., Stroh, F., Hoffmann, L., and Riese, M.: Filamentary structure in chemical tracer distributions near the subtropical jet following a wave breaking event, Atmos. Chem. Phys., 13, 10517-10534, doi:10.5194/acp13-10517-2013, 2013.

Ungermann, J., Ern, M., Kaufmann, M., Müller, R., Spang, R., Ploeger, F., Vogel, B., and Riese, M.: Observations of PAN and 
its confinement in the Asian summer monsoon anticyclone in high spatial resolution, Atmos. Chem. Phys., 16, 8389-8403, doi:10.5194/acp-16-8389-2016, 2016.

Vaughan, G. and Timmis, C.: Transport of near-tropopause air into the lower midlatitude stratosphere, Q. J. Roy. Meteor. Soc., 124, 1559-1578, 1998.

Vernier, J. P., Fairlie, T. D., Natarajan, M., Wienhold, F. G., Bian, J., Martinsson, B. G., Crumeyrolle, S., Thomason, L. W., and Bedka, K. M.: Increase in upper tropospheric and lower stratospheric aerosol levels and its potential connection with Asian pollution, J. Geophys. Res., 120, 1608-1619, doi:10.1002/2014JD022372, 2015.

Vogel, B., Konopka, P., Grooß, J.-U., Müller, R., Funke, B., LópezPuertas, M., Reddmann, T., Stiller, G., von Clarmann, T., and Riese, M.: Model simulations of stratospheric ozone loss caused by enhanced mesospheric $\mathrm{NO}_{x}$ during Arctic Winter 2003/2004, Atmos. Chem. Phys., 8, 5279-5293, doi:10.5194/acp-8-52792008, 2008

Vogel, B., Feck, T., and Grooß, J.-U.: Impact of stratospheric water vapor enhancements caused by $\mathrm{CH}_{4}$ and $\mathrm{H}_{2}$ increase on polar ozone loss, J. Geophys. Res., 116, D05301, doi:10.1029/2010JD014234, 2011a.

Vogel, B., Pan, L. L., Konopka, P., Günther, G., Müller, R., Hall, W., Campos, T., Pollack, I., Weinheimer, A., Wei, J., Atlas, E. L., and Bowman, K. P.: Transport pathways and signatures of mixing in the extratropical tropopause region derived from Lagrangian model simulations, J. Geophys. Res., 116, D05306, doi:10.1029/2010JD014876, 2011b.

Vogel, B., Günther, G., Müller, R., Grooß, J.-U., Hoor, P., Krämer, M., Müller, S., Zahn, A., and Riese, M.: Fast transport from Southeast Asia boundary layer sources to northern Europe: rapid uplift in typhoons and eastward eddy shedding of the Asian monsoon anticyclone, Atmos. Chem. Phys., 14, 12745-12762, doi:10.5194/acp-14-12745-2014, 2014.
Vogel, B., Günther, G., Müller, R., Grooß, J.-U., and Riese, M.: Impact of different Asian source regions on the composition of the Asian monsoon anticyclone and of the extratropical lowermost stratosphere, Atmos. Chem. Phys., 15, 13699-13716, doi:10.5194/acp-15-13699-2015, 2015.

Waymark, C., Walker, K. A., Boone, C. D., and Bernath, P. F.: ACEFTS versions 3.0 data set: validation and data processing update, Ann. Geophys.-Italy, 56, 1-7, doi:10.4401/ag-6339, 2013.

Wu, X. and Lü, D.: Ten-year climatological features and air origin of midlatitude double tropopauses, Adv. Atmos. Sci., 32, 1592 1602, doi:10.1007/s00376-015-5036-4, 2015.

Zahn, A., Weppner, J., Widmann, H., Schlote-Holubek, K., Burger, B., Kühner, T., and Franke, H.: A fast and precise chemiluminescence ozone detector for eddy flux and airborne application, Atmos. Meas. Tech., 5, 363-375, doi:10.5194/amt-5-363-2012, 2012.

Zahn, A., Christner, E., van Velthoven, P. F. J., Rauthe-Schöch, A., and Brenninkmeijer, C. A. M.: Processes controlling water vapor in the upper troposphere/lowermost stratosphere: An analysis of 8 years of monthly measurements by the IAGOSCARIBIC observatory, J. Geophys. Res., 119, 11505-11525, doi:10.1002/2014JD021687, 2014.

Zöger, M., Schiller, C., and Eicke, N.: Fast in situ hygrometers: A new family of balloonborne and airborne Lyman- $\alpha$ photofragment fluorescence hygrometers, J. Geophys. Res., 104, 18071816, 1999. 